\title{
Analytical Similarity Assessment of Biosimilars: Global Regulatory Landscape, Recent Studies and Major Advancements in Orthogonal Platforms
}

\author{
Neh Nupur ${ }^{1 \dagger}$, Srishti Joshi ${ }^{1 \dagger}$, Davy Gulliarme $e^{2,3}$ and Anurag S. Rathore ${ }^{1 *}$ \\ ${ }^{1}$ Department of Chemical Engineering, IIT Delhi, Hauz Khas, New Delhi, India, ${ }^{2}$ Institute of Pharmaceutical Sciences of Western \\ Switzerland (ISPSO), University of Geneva, Geneva, Switzerland, ${ }^{3}$ School of Pharmaceutical Sciences, University of Geneva, \\ Geneva, Switzerland
}

OPEN ACCESS

Edited by:

Christoph Herwig,

Vienna University of Technology,

Austria

Reviewed by:

Chang-Han Lee,

Seoul National University, South Korea

Ana Margarida Goncalves Carvalho

Dias,

New University of Lisbon, Portugal

*Correspondence:

Anurag S. Rathore

asrathore@biotechcmz.com

${ }^{+}$These authors have contributed equally to this work and share first authorship

Specialty section:

This article was submitted to Bioprocess Engineering,

a section of the journal

Frontiers in Bioengineering and

Biotechnology

Received: 09 December 2021

Accepted: 07 January 2022

Published: 09 February 2022

Citation:

Nupur N, Joshi S, Gulliarme D and Rathore AS (2022) Analytical Similarity

Assessment of Biosimilars: Global

Regulatory Landscape, Recent Studies and Major Advancements in Orthogonal Platforms.

Front. Bioeng. Biotechnol. 10:832059. doi: 10.3389/fbioe.2022.832059
Biopharmaceuticals are one of the fastest-growing sectors in the biotechnology industry. Within the umbrella of biopharmaceuticals, the biosimilar segment is expanding with currently over 200 approved biosimilars, globally. The key step towards achieving a successful biosimilar approval is to establish analytical and clinical biosimilarity with the innovator. The objective of an analytical biosimilarity study is to demonstrate a highly similar profile with respect to variations in critical quality attributes (CQAs) of the biosimilar product, and these variations must lie within the range set by the innovator. This comprises a detailed comparative structural and functional characterization using appropriate, validated analytical methods to fingerprint the molecule and helps reduce the economic burden towards regulatory requirement of extensive preclinical/ clinical similarity data, thus making biotechnological drugs more affordable. In the last decade, biosimilar manufacturing and associated regulations have become more established, leading to numerous approvals. Biosimilarity assessment exercises conducted towards approval are also published more frequently in the public domain. Consequently, some technical advancements in analytical sciences have also percolated to applications in analytical biosimilarity assessment. Keeping this in mind, this review aims at providing a holistic view of progresses in biosimilar analysis and approval. In this review, we have summarized the major developments in the global regulatory landscape with respect to biosimilar approvals and also catalogued biosimilarity assessment studies for recombinant DNA products available in the public domain. We have also covered recent advancements in analytical methods, orthogonal techniques, and platforms for biosimilar characterization, since 2015. The review specifically aims to serve as a comprehensive catalog for published biosimilarity assessment studies with details on analytical platform used and critical quality attributes (CQAs) covered for multiple biotherapeutic products. Through this compilation, the emergent evolution of techniques with respect to each CQA has also been charted and discussed. Lastly, the information resource of published biosimilarity assessment studies, created during literature search is anticipated to serve as a helpful reference for biopharmaceutical scientists and biosimilar developers.

Keywords: analytical similarity, biosimilars, critical quality attributes, orthogonal analytical tools, regulatory guidelines 


\section{INTRODUCTION}

Biologics or biotherapeutics are rDNA products used to diagnose, prevent, treat, and cure medical conditions and include a diverse category of products (i.e., proteins, enzymes, peptides, vaccines to name a few). Biotherapeutics are structurally complex compared to small molecules (USFDA, 2018). Currently, biopharmaceuticals are one of the fastest-growing sectors in the biotechnology industry. In the last decade, the landscape for biologics has evolved at an accelerated rate globally with market size of USD 254.9 billion as of 2017 and expected to reach USD 580.5 billion by 2026 at a Compound Annual Growth Rate $\left(\mathrm{CAGR}^{1}\right)$ of $9.5 \%$ (2018-2026) (Global, 2018).

As the innovator (aka originator/reference) molecule reaches patent cliff, it paves way for commercialization of biosimilars which are "highly similar" to the innovator in terms of structure and function, notwithstanding minor variations in clinically inactive components and should have no clinically meaningful differences in terms of safety, purity, and potency of the drug product $\left(\mathrm{DP}^{2}\right)$ (USFDA, 2019). This needs to be thoroughly characterized during product development. The product attributes that are critical to the safety, efficacy, and potency of the product are classified as critical quality attributes (CQAs) (Eon-Duval et al., 2012). This exercise that is conducted to establish comparability between the reference product and its intended biosimilar is known as similarity assessment (aka biosimilarity) and comprises detailed comparative physicochemical and functional characterization using appropriate, validated analytical methods (Nupur et al., 2016, 2018; Joshi and Rathore, 2020). As structural attributes are molecule-dependent, CQAs may vary to a certain degree amongst the different modalities. For example, glycosylation is typically a CQA for proteins produced in the eukaryotic systems, such as monoclonal antibodies (mAbs) produced in the mammalian cells. For therapeutics with prokaryotic hosts (such as Escherichia coli), glycosylation is not an attribute of concern. Hence, requirements for analytical platforms for characterization and biosimilarity assessments are tailored to be modality-specific and within the larger domain of rDNA products, so are the regulatory requirements. Analytical platforms play a dynamic role in biopharmaceutical and biosimilar manufacturing and in general serves to control/ monitor the process. A typical bioprocess train for biosimilar development and associated analysis commonly required at different stages of manufacturing are illustrated in Figure 1.

The requirement of unambiguous biosimilarity demonstration brings us to the concept of orthogonality. Implementation of orthogonal tools (differing in their principle of operation) is invaluable to demonstrate unambiguity in the comparative profiles of CQAs, especially in the cases where the primary

${ }^{1} \mathrm{CAGR}$ is a geometric progression ratio that provides a constant rate of return over the time period.

${ }^{2} \mathrm{DP}$ is the finished dosage form, for example, a tablet, capsule or solution that contains an active pharmaceutical ingredient, generally, but not necessarily, in association with inactive ingredients. technique is qualitative or the CQA is dynamic (i.e., cannot be mapped completely by one technique). The United States Food and Drug Administration (USFDA) non-binding guidance for industry on "Development of Therapeutic Protein Biosimilars: Comparative Analytical Assessment and Other Quality-Related Considerations," quotes that "methods that use different physicochemical or biological principles to assess the same attribute are especially valuable, because they provide independent data to support the quality of that attribute" and have pointed out the importance of adding orthogonal tools to analytical assessment (USFDA, 2019). A classic example of this is size variants, where orthogonal analytical techniques have been widely employed to 1) cover the breadth of the size range (soluble aggregates $<$ sub visible $<$ visible $<$ insoluble aggregates) and 2) to independently quantify size aggregates in the same size range (orthogonal tools for size variants assessment are discussed in Section 2.2.4.1). Other attributes exemplifying the use of orthogonal tools include higher-order structure (HOS), glycosylation, and charge variants (discussed under Section 4).

Analytical characterization of CQAs for different modalities has been reviewed in some publications (Fekete et al., 2013, 2016; Jacobs et al., 2016, 2017; Santos-Neto et al., 2021). However, the current review focuses on major developments in regulatory approvals and orthogonal analytical platforms for biosimilarity assessment. The global regulatory landscape with respect to biosimilar approvals as well as that in the analytical platforms for similarity studies (till July 2021) has been summarized, with particular focus on progress made in the last 5 years (since 2015). Finally, a discussion on evolution and future trajectory of analytical similarity platforms is also presented. Overall, this review serves as a useful repository of references to help biosimilar manufacturers in designing suitable analytical platforms for similarity studies.

All abbreviations appearing in this publication, including supplementary information have been tabulated as Supplementary Table S1. Definitions and meanings of domain specific terminology have been listed in Supplementary Table S2.

\section{GLOBAL LANDSCAPE ON BIOSIMILAR APPROVALS}

Following the patent cliff of certain innovator products and the growing support from the major regulatory agencies, there has been a steady increase in the number of biosimilar approvals. At present, region and country-specific biosimilar regulatory pathways and guidance are at different stages of development and implementation (Rathore and Bhargava, 2020; 2021a; 2021b; 2021c). There is a growing interest in increasing global harmonization of the regulatory guidelines for biosimilar development including selection of the reference product, nomenclature, and the design of analytical, non-clinical, or clinical biosimilarity studies. A global agreement on the regulatory requirement for the biosimilars would facilitate standardization of product quality and is likely to positively impact the reception and acceptance of biosimilars worldwide 


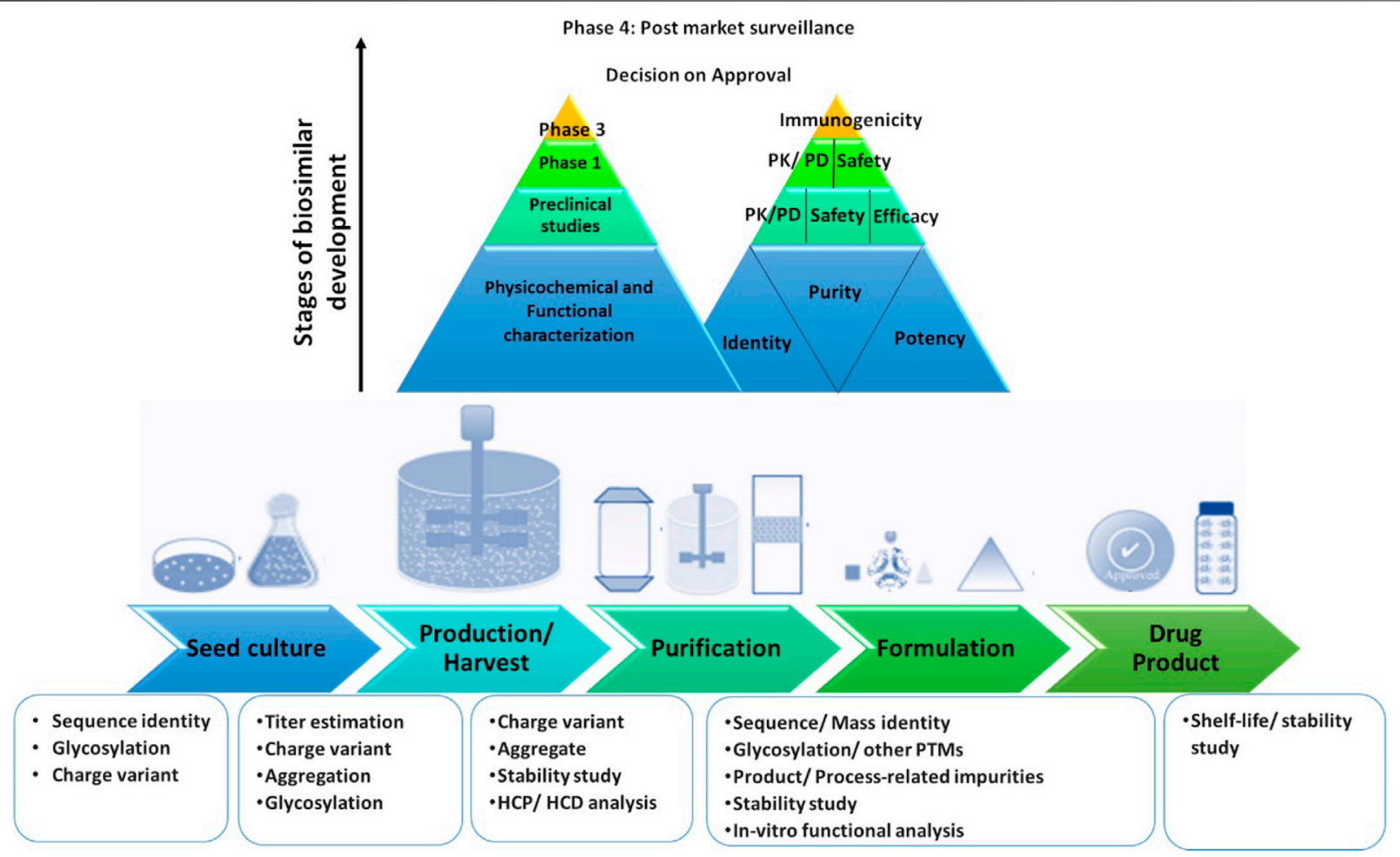

FIGURE 1 | Bioprocess train with multiple stages of development during biosimilar manufacturing. PK, Pharmacokinetics; PD, Pharmacodynamics; PTM, Post translational modifications; HCP, Host Cell Protein; HCD, Host Cell DNA.

(WHO, 2009, 2013; Kang H.-N. et al., 2020). A brief region and country-wise account of global status on regulatory guidelines for biosimilar approvals are presented in Table 1.

The European Medicines Agency (EMA) pioneered the legal framework and regulatory approval pathway for biosimilars in 2005, paving the way for other jurisdictions around the globe (Gherghescu and Delgado-Charro, 2020). In alignment with the International Council for Harmonization (ICH) guidelines, the EMA's "Guideline on Similar Biological Medicinal Products" states that similarity to the innovator needs to be established in terms of quality characteristics, biological activity, safety, and efficacy based on a comprehensive, head-to-head biosimilarity exercise for characterization of the quality of the DP and the approval is subjected to the totality-of-evidence presented (EMA, 1996, 1999, 2005; CHMP, 2005, 2014). The World Health Organization (WHO) adopted similar guidelines on the evaluation of Similar Biotherapeutic Products (SBPs) in 2009 to ensure better access to safe and effective SBPs worldwide through global harmonization of the regulatory framework for licensure (WHO, 2009). The WHO laid the foundation for other regulatory authorities to introduce their respective guidelines by giving to the national regulatory authorities (NRAs) the flexibility to adapt approval pathways according to their needs. Around the same time, Biologics Price Competition and Innovation Act (BPCI) were developed in the US that initiated the biosimilar approval pathway under USFDA. Since then, several countries have laid down and implemented a regulatory framework for biosimilar approval for its commercial use within their jurisdiction (Table 1). All guidance documents thus far emphasize the demonstration of biosimilarity via extensive structural and functional characterization followed by nonclinical, pharmacokinetic, and clinical studies. The degree of biosimilarity with respect to product quality determines the scope and breadth of the required non-clinical and clinical data, on a case-by-case basis, dependent on the product class/ modality. The comparative clinical studies are encouraged to be specifically developed to rule out clinically relevant differences in safety or efficacy between the biosimilar and the innovator, in order to confirm biosimilarity (WHO, 2013).

The global regulatory landscape continues to evolve in response to the mushrooming biosimilar industry, with close to 600 approved biosimilars for 45 reference products in over 50 countries, to date. In addition to Table 1, a comprehensive region/country-wise list of $\mathrm{mAb}$ and non-mAb biosimilar approvals has been tabulated in Supplementary Table S3. Due to several factors such as clinical indications, market size, patent cliffs, and the need for affordable alternatives, mAbs constitute a major segment in the overall biosimilars portfolio. This is evidenced by a total of 249 biosimilars that currently populate the market for 12 reference products. Of these, the leading mAbs include anti-HER2 trastuzumab (60), anti-CD20 rituximab (53), anti-TNF $\alpha$ adalimumab (38) and infliximab (33), and anti-VEGF bevacizumab (31), and the anti-TNF Fc-fusion protein, etanercept (26) (Figure 2A). The majority of these approvals 
TABLE 1 | A region/country-wise account of regulatory guidelines for biosimilar approvals to dateJuly, 2021.

\begin{tabular}{|c|c|c|c|c|c|c|}
\hline Region & Countries & Regulatory agency & Year & $\begin{array}{l}\text { Adopted from/Aligned } \\
\text { with }\end{array}$ & $\begin{array}{l}\text { Biosimilar } \\
\text { approvals } \\
\text { (till date) }\end{array}$ & References \\
\hline Europe & $\begin{array}{l}\text { European } \\
\text { Union }\end{array}$ & European Medical Agency (EMA) & 2005 & $\begin{array}{l}\text { Committee for Medicinal } \\
\text { Products for Human Use and } \\
\text { International Council for } \\
\text { Harmonization }(\mathrm{ICH})\end{array}$ & 69 & $\begin{array}{l}\text { EMA (1996), EMA } \\
\text { (1999),EMA (2005), EMA } \\
\text { (2020), CHMP (2005), } \\
\text { CHMP (2014) }\end{array}$ \\
\hline \multirow[t]{2}{*}{$\begin{array}{l}\text { North } \\
\text { America }\end{array}$} & $\begin{array}{l}\text { United States } \\
\text { (US) }\end{array}$ & Food and Drug Administration (FDA) & $\begin{array}{l}\text { Initiated in } 2010 \\
\text { and finalized in } \\
2015\end{array}$ & $\begin{array}{l}\text { Biologics Price Competition and } \\
\text { Innovation Act, } 2010 \text { for Biologic } \\
\text { License Application and Section } \\
351(a) \text { and } 351(k) \text { of the Public } \\
\text { Health Service Act }\end{array}$ & 34 & $\begin{array}{l}\text { USFDA (2015), USFDA } \\
\text { (2019), USFDA (2021) }\end{array}$ \\
\hline & Canada & $\begin{array}{l}\text { Biologics and Genetic Therapies } \\
\text { Directorate under Health Canada }\end{array}$ & $\begin{array}{l}\text { Initiated in } 2010 \\
\text { and finalized in } \\
2016\end{array}$ & EMA, USFDA, and WHO & 26 & $\begin{array}{l}\text { Canada (2016), Wojtyra } \\
\text { (2021) }\end{array}$ \\
\hline \multirow[t]{11}{*}{ Asia } & Japan & $\begin{array}{l}\text { Pharmaceuticals and Medical } \\
\text { Devices Agency }\end{array}$ & 2009 & EMA & 28 & $\begin{array}{l}\text { PMDA (2020), Rathore } \\
\text { and Bhargava (2021a) }\end{array}$ \\
\hline & South Korea & Ministry of Food and Drug Safety & $\begin{array}{l}\text { Initiated in } 2009 \\
\text { and finalized in } \\
2014\end{array}$ & EMA and $\mathrm{WHO}$ & 15 & $\begin{array}{l}\text { MFDS (2020), Rathore } \\
\text { and Bhargava (2021a) }\end{array}$ \\
\hline & India & $\begin{array}{l}\text { Central Drugs Standard Control } \\
\text { Organization and the Review } \\
\text { Committee on Genetic Manipulation }\end{array}$ & $\begin{array}{l}\text { Initiated in } 2012 \\
\text { and revised in } \\
2016\end{array}$ & EMA and USFDA & 103 & $\begin{array}{l}\text { DBT (2016), CDSCO } \\
\text { (2020), Rathore and } \\
\text { Bhargava (2021a) }\end{array}$ \\
\hline & China & $\begin{array}{l}\text { Center for Drug Evaluation under } \\
\text { National Medical Products } \\
\text { Administration }\end{array}$ & $\begin{array}{l}\text { Initiated in } 2014 \\
\text { and finalized in } \\
2015\end{array}$ & EMA and USFDA & 14 & $\begin{array}{l}\text { GaBI (2021), Rathore } \\
\text { and Bhargava (2021a) }\end{array}$ \\
\hline & Malaysia & $\begin{array}{l}\text { National Pharmaceutical Regulatory } \\
\text { Agency }\end{array}$ & $\begin{array}{l}\text { Initiated in } 2008 \\
\text { and reframed in } \\
2009\end{array}$ & EMA and $\mathrm{WHO}$ & 25 & $\begin{array}{l}\text { NPRA (2021), Rathore } \\
\text { and Bhargava (2021a) }\end{array}$ \\
\hline & Indonesia & $\begin{array}{l}\text { National Agency for Drug and Food } \\
\text { Control }\end{array}$ & 2015 & $\mathrm{ICH}$ and EMA & 20 & $\begin{array}{l}\text { Kang et al. (2021), } \\
\text { Rathore and Bhargava }\end{array}$ \\
\hline & Singapore & Health Products Regulation Group & 2009 & EMA & 7 & 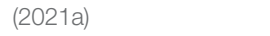 \\
\hline & Thailand & Food and Drug Administration & 2013 & $\mathrm{WHO}$ & 13 & \\
\hline & Iran & $\begin{array}{l}\text { Food and Drug Organization under } \\
\text { Ministry of Health and Medical } \\
\text { Education }\end{array}$ & 2014 & $\mathrm{WHO}$ & 26 & \\
\hline & Jordan & Food and Drug Administration & 2015 & EMA & 9 & \\
\hline & Russia & $\begin{array}{l}\text { Министерство здравоочранения } \\
\text { Российской Федерации; } \\
\text { Rosminzdrav, Minzdrav }\end{array}$ & & & 34 & $\begin{array}{l}\text { GaBI (2020), Kang et al. } \\
\text { (2021) }\end{array}$ \\
\hline Australia & Australia & Therapeutic Goods Administration & $\begin{array}{l}\text { Initiated in } 2008 \text {, } \\
\text { finalized in } 2013 \\
\text { and revised in } \\
2018\end{array}$ & EMA & 26 & $\begin{array}{l}\text { TGA (2018), Health } \\
\text { (2021) }\end{array}$ \\
\hline \multirow[t]{8}{*}{$\begin{array}{l}\text { Latin } \\
\text { America }\end{array}$} & Argentina & $\begin{array}{l}\text { Administracion Nacional de } \\
\text { Medicamentos, Alimentos y } \\
\text { Tecnologia Medica }\end{array}$ & 2008 & EMA & 29 & $\begin{array}{l}\text { GaBl (2019), Ortiz-Prado } \\
\text { et al. (2020), } \\
\text { Rathore and Bhargava }\end{array}$ \\
\hline & Brazil & $\begin{array}{l}\text { Agencia Nacional de Vigilancia } \\
\text { Sanitaria }\end{array}$ & 2010 & $\mathrm{WHO}$ & 21 & $(2021 b)$ \\
\hline & Mexico & $\begin{array}{l}\text { Federal Commission for the } \\
\text { Protection against Sanitary Risks }\end{array}$ & $\begin{array}{l}\text { Initiated in } 2011 \\
\text { and reframed in } \\
2013\end{array}$ & & 6 & \\
\hline & Peru & Ministerio de Salud & 2016 & WHO, FDA, and EMA & 5 & \\
\hline & Colombia & $\begin{array}{l}\text { Ministerio de Salud y Proteccion } \\
\text { Social }\end{array}$ & 2013 & & 3 & \\
\hline & Chile & Agencia Nacional de Medicamentos & $\begin{array}{l}\text { Initiated in } 2011 \\
\text { and finalized in } \\
2014\end{array}$ & & 15 & \\
\hline & Venezuela & $\begin{array}{l}\text { Instituto Nacional de Higiene "Rafael } \\
\text { Rangel" }\end{array}$ & 2012 & & 1 & \\
\hline & Cuba & $\begin{array}{l}\text { Center for State Control on the } \\
\text { Quality of Drugs }\end{array}$ & 2011 & $\mathrm{WHO}$ & 16 & \\
\hline
\end{tabular}


TABLE 1 | (Continued) A region/country-wise account of regulatory guidelines for biosimilar approvals to dateJuly, 2021.

\begin{tabular}{|c|c|c|c|c|c|c|}
\hline Region & Countries & Regulatory agency & Year & $\begin{array}{l}\text { Adopted from/Aligned } \\
\text { with }\end{array}$ & $\begin{array}{l}\text { Biosimilar } \\
\text { approvals } \\
\text { (till date) }\end{array}$ & References \\
\hline \multirow[t]{3}{*}{ Africa } & Egypt & $\begin{array}{l}\text { Central Administration for } \\
\text { Pharmaceutical Affairs with National } \\
\text { Organization for Research and } \\
\text { Control of Biologics under Egyptian } \\
\text { Drug Authority }\end{array}$ & 2013 & & 4 & $\begin{array}{l}\text { Pategou (2020), Kang } \\
\text { et al. (2021) }\end{array}$ \\
\hline & Ghana & Food and Drugs Authority & $\begin{array}{l}\text { Initiated in } 2013 \\
\text { and reframed in } \\
2019\end{array}$ & & 13 & \\
\hline & South Africa & $\begin{array}{l}\text { South African Health Product } \\
\text { Regulatory Authority }\end{array}$ & $\begin{array}{l}\text { Initiated in } 2010 \\
\text { and reframed in } \\
2014\end{array}$ & EMA & 2 & \\
\hline
\end{tabular}

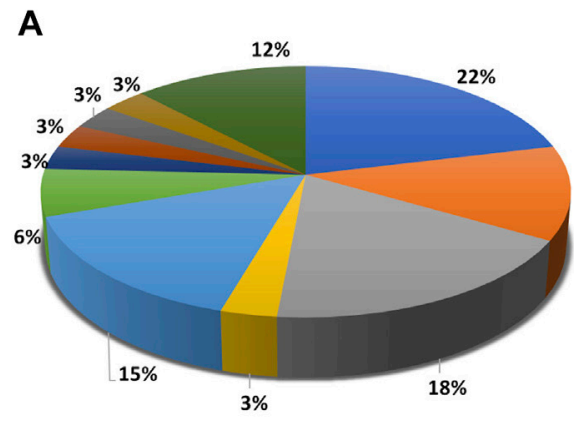

$\mathbf{B}$

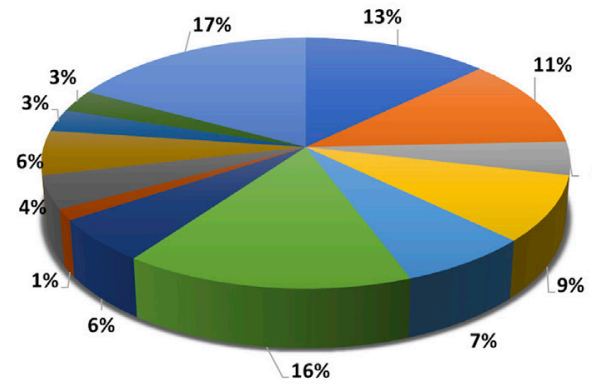

rituximab

adalimumab

bevacizumab

infliximab

$12 \%$

ranibizumab

v denosumab

abciximab

nimotuzumab

- omalizumab

- eculizumab

- etanercept

a filgrastim

angilgrastim

- teriparatide

numan insulin

insulin glargine

$4 \%$ epoetin alfa

a interferon alfa-2b

anterferon beta-1a

- follitropin alfa

ndarbepoetin alfa

ar-HCG

- somatropin

athers

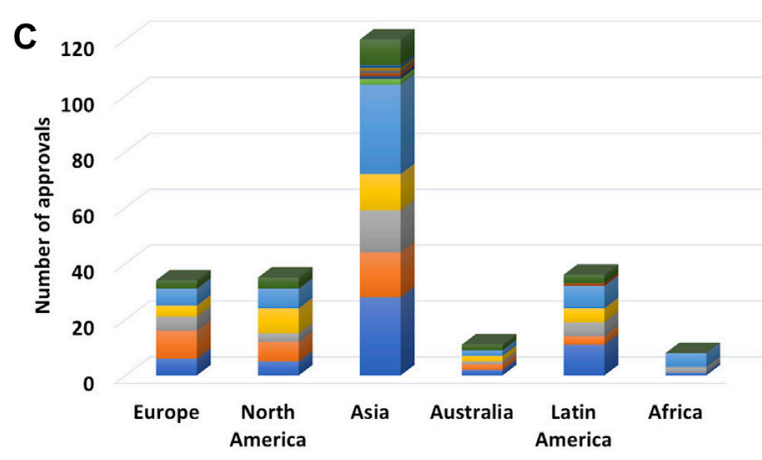

D 200
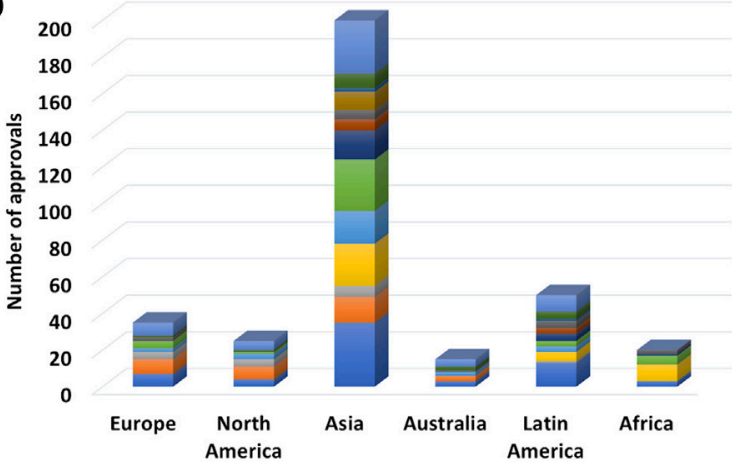

FIGURE 2 | Trend in biosimilar approval for different modalities depicted as percentage of total approvals for a given biologic under (A) mAbs and (B) non-mAbs and global biosimilar approvals (in numbers) across continents i.e., Europe, North America, Asia, Australia, Latin America, and Africa for (C) mAbs and (D) non-mAbs.

have been granted in Asia (50\%) followed by Latin America (15\%), Europe (14\%), North America (14\%), Australia (4\%), and Africa (3\%) (Figure 2B). Taking the rest of the modalities together as non-mAbs, a total of 348 biosimilars for 33 reference products belonging to filgrastim (65, GCSF receptor binding) followed by epoetin alfa (41, JAK-STAT receptor binding), human insulin (37, insulin receptor binding), pegfilgrastim (32, GCSF receptor binding), insulin glargine (28, insulin receptor binding), and interferon alfa- $2 \mathrm{~b}(21, \mathrm{IFN}-\alpha / \beta$ receptor binding) have been approved so far (Figure 2C). The geographic spread of these approvals is similar to that of mAbs with a maximum number of biosimilar approvals granted in Asia (58\%) followed by Latin America (15\%), Europe (10\%), North America (7\%), Africa (6\%) and Australia (4\%) (Figure 2D).

Recent patent expirations (2020-21) include ranibizumab (2020-US) and eculizumab (2020-US, 2021-EU). Other major 


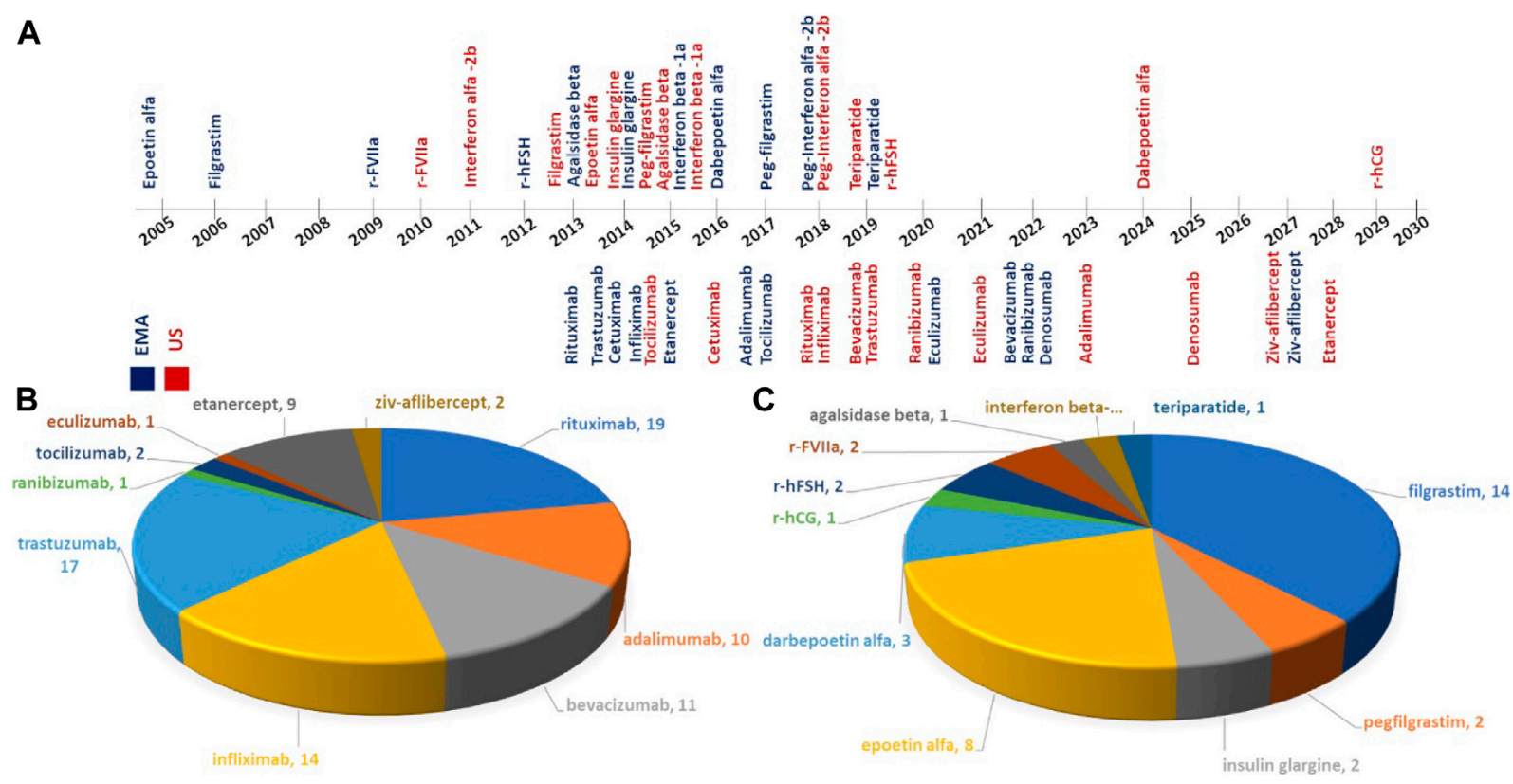

FIGURE 3 | (A) Timeline on patent expirations of reference products in European Medicines Agency; EMA (Moorkens et al., 2020) and U.S. Food and Drug Administration; USFDA (Derbyshire and Shina, 2019), publications on analytical similarity studies for biosimilars under (B) mAbs, and (C) non-mAbs.

biologics including blockbuster drugs nearing patent cliff in this decade include Bevacizumab (2022-EU), ranibizumab (2022EU), Denosumab (EU-2020), adalimumab (US-2023), Denosumab (US-2025), Ziv-aflibercept (EU/US-2021 and Etanercept (2028-US) for $\mathrm{mAb}$ based biologics and Dabepoetin alpha (2024-US) and r-hCG (2029-US) in non$\mathrm{mAb}$ biologics (Figure 3A).

The affordability of biosimilars largely depends on remissions in clinical studies granted on the basis of analytical and functional biosimilarity assessment data presented to the regulators. Despite a large number of approvals, public availability of information related to biosimilarity assessment is scattered and limited. Here, we have collected information with respect to analytical biosimilarity studies published as peer-reviewed research articles and offer a comprehensive account of the same in the following section.

\subsection{Analytical Biosimilarity Assessment in the Published Literature}

Head-to-head structural and functional biosimilarity assessment is a non-trivial, resource-intensive exercise since there is a need to use multiple methods for analytical and functional characterization. Most regulatory guidelines recommend the use of a gamut of orthogonal, high-resolution, analytical tools for qualitative and quantitative characterization of CQAs. Although several biosimilars have been approved to date, publicly available repositories of published literature on analytical biosimilarity studies remain limited (Ishii-Watabe and Kuwabara, 2019; Alsamil et al., 2020; Ratih et al., 2021; Safdar et al., 2021). In this section, we have focused on peer- reviewed analytical biosimilarity studies published so far, with a focus on analytical platforms used for characterization of each CQA. The methodology adopted for the selection of relevant publications from search engines has been detailed in Supplementary Material. The final database consisted of 116 publications presenting analytical biosimilarity studies for approved/intended biosimilars available in the public domain with details on the CQAs assessed and analytical tools used to date (Supplementary Table S4).

To the best of our knowledge, the first peer-reviewed biosimilarity study was published in 2006 where biophysical comparability of Epoetin alfa was carried out comparing the analytical profiles of Eprex ${ }^{\circledR}$ (prefilled syringes) with the innovator, namely Epogen ${ }^{\circledR}$. It is a recombinant human erythropoietin that stimulates red blood cell production and is approved by FDA for use in treatment of anemia due to chronic kidney disease or cancer treatments. (Deechongkit et al., 2006). The innovator product Epogen ${ }^{\circledR}$ manufactured by Amgen reached patent cliff in 2005 in Europe and 2013 in US following which several biosimilars and intended copies have entered the markets. The market for the molecule continues to grow (USD9,243.12 million in 2020), and is projected to reach USD14,414.59 million by 2028. The annual sales of Epogen ${ }^{\circledR}$, the innovator product was reported at 598 million USD for financial year 2020 (Amgen, 2021; Nerkar et al., 2021). Since epoetin alpha, $10 \mathrm{mAbs}$ and 15 non $\mathrm{mAbs}$ have reached the patent cliff in either the US or EMA and the peer-reviewed biosimilarity studies have been published for most off-patent products (Figure 3A, Supplementary Table S5). About 80 analytical biosimilarity studies covering 8 off-patent mAbs (i.e., rituximab, trastuzumab, bevacizumab, infliximab, adalimumab, 
ranibizumab, tocilizumab, and eculizumab) and 2 Fc-fusion proteins (i.e., etanercept and ziv-aflibercept) have been published so far (till July 2021). Interestingly, there are few instances where analytical studies have been published for the parent molecule (ziv-aflibercept) yet to reach patent expiration (due date 2027) (Hermosilla et al., 2020; Shen et al., 2021). Similarly, in the case of non-mAbs, 36 analytical biosimilarity studies covering 11 non-mAbs (i.e., filgrastim, peg-filgrastim, epoetin- $\alpha$, darbepoetin- $\alpha$, interferon- $\beta$, recombinant activated factor VII (rFVIIa), insulin glargine, recombinant human follicle stimulating hormone (r-FSH), agalsidase- $\beta$, recombinant human chorionic gonadotropin (r-hCG), and teriparatide) are accessible in the public domain (till July 2021). The most represented molecules in these studies include rituximab (19), trastuzumab (17), filgrastim (14), infliximab (14), bevacizumab (11), adalimumab (10), and etanercept (9) (Figures 3B, C).

Broadly, the most relevant CQAs of biotherapeutic products can be categorized under primary structure, higher-order structures (HOS), glycosylation (eukaryotic hosts), productrelated variants, and process-related variants. The primary structure is further divided into intact/subunit mass analysis, amino acid sequence/peptide mapping, and disulfide bridge/free sulfhydryl group; HOS into the secondary structure, tertiary structure, and conformational stability; glycosylation into oligosaccharide pattern, glycopeptide mapping, and monosaccharide/sialic acid content; product-related variants into size variants, charge variants and related proteins arising out of post-translational modifications, i.e., aggregates, fragments, C-terminal lysine loss, $\mathrm{N}$-terminal pyroglutamate cyclization, methionine oxidation, asparagine deamidation, aspartate isomerization, glycation, phosphorylation, acetylation, acylation, misfolding and process-related variants into host cell proteins (HCPs) and host cell DNA (HCD). A minimum requirement of at least one technique under each of the above-mentioned categories is mandatory for assessment, except in cases where the nature of the therapeutic of interest allows for the exclusion of analyzing certain attributes. For example, biosimilars expressed in E. coli do not require glycosylation analysis as the expression system is not capable of performing glycosylation.

For interested readers, a comprehensive account of CQA-wise and tool-wise analytical biosimilarity studies in published literature covering orthogonal analytical tools has been tabulated in Supplementary Table S6. From published studies, most assessed CQAs were primary structure (peptide mapping/ amino acid sequence covered in 76 studies), followed by productrelated variants (size variants covered in 75 studies), HOS (tertiary structure covered in 63 studies), and glycosylation (58 studies). This is not surprising as biosimilarity exhibited across the structural hierarchy is indicative of preservation of the functionality and hence efficacy of the intended biosimilar.

While assessing biosimilarity, one is really looking at the structural fingerprint of the biosimilar DP/DS and comparing it to the innovator. The strength of the evidence gathered is hence directly dependent on the resolution and sensitivity of the techniques employed. Moreover, in certain instances, one technique per attribute may not be sufficient as the attribute in question may be multi-faceted and hence requires multiple orthogonal tools. HOS and size variants are two such examples. Hence orthogonal tools serve as a means to 1) corroborate evidence for biosimilarity and 2) map multiple facets of a complex attribute independently, with an overall aim of reducing ambiguity. Having said that, there is significant commonality in CQAs for therapeutic molecules as elements of structural identity and integrity such as primary and HOS which are applicable to all proteins. Therefore, primarily the biosimilarity platforms consist of established biophysical techniques used in protein characterization. Over time and follow-on technical advancements, orthogonal assessment means have corroborated the skeleton of analytical characterization platforms (Figure 4). Major technical developments since 2015 have been outlined and discussed below.

\subsection{Recent Advancements and Orthogonality in Analytical Similarity Assessment}

As outlined in the USFDA guidelines on the comparative analytical assessment of biosimilars, detailed analysis of CQAs should be conducted using orthogonal analytical platforms including both established biophysical tools and new technologies, since each technique has its own merits and demerits (USFDA, 2019). The development of methods and techniques for orthogonal assessment of CQAs is hence a burgeoning field and over the years, some of these methods and techniques have been adopted for routine biosimilarity studies (Supplementary Tables S6, S7 and Figure 4). In comparison to other CQAs, HOS and/or stability are the most represented with respect to publications reporting application of a new technology/technique for comparative analysis of biotherapeutics (covered in 28 studies) followed by glycan profiling (covered in 21 studies), charge variants (covered in 15 studies), peptide mapping (covered in 11 studies), size variants (covered in seven studies), and other attributes (other PTMs, glycation, disulfide bond, free sulfhydryl content, HCPs, and effector binding). Data acquisition aside, there has also been an increase in publications related to the application of advanced statistical methods for the evaluation of chromatography/ spectroscopy data for comparative analysis (nine studies).

\subsubsection{Primary Structure}

Confirmation of primary structure involves mapping of the amino-acid sequence (sequence identity) and measuring the exact mass (mass-identity) of the biosimilar compared to the innovator (Figure 5). Sequence identity can be established by both Edman degradation and mass spectrometry (MS). Edman degradation, a traditional tool that involves successive removal of $\mathrm{N}$-terminal amino acids by chemical methods, has featured in several publications across the years (Lee et al., 2013; Crobu et al., 2014). However, MS has increasingly become the more popular technique for both sequence and mass identity due to its sensitivity, versatility, fast turnaround and enhanced resolution. Moreover, additional information related to 


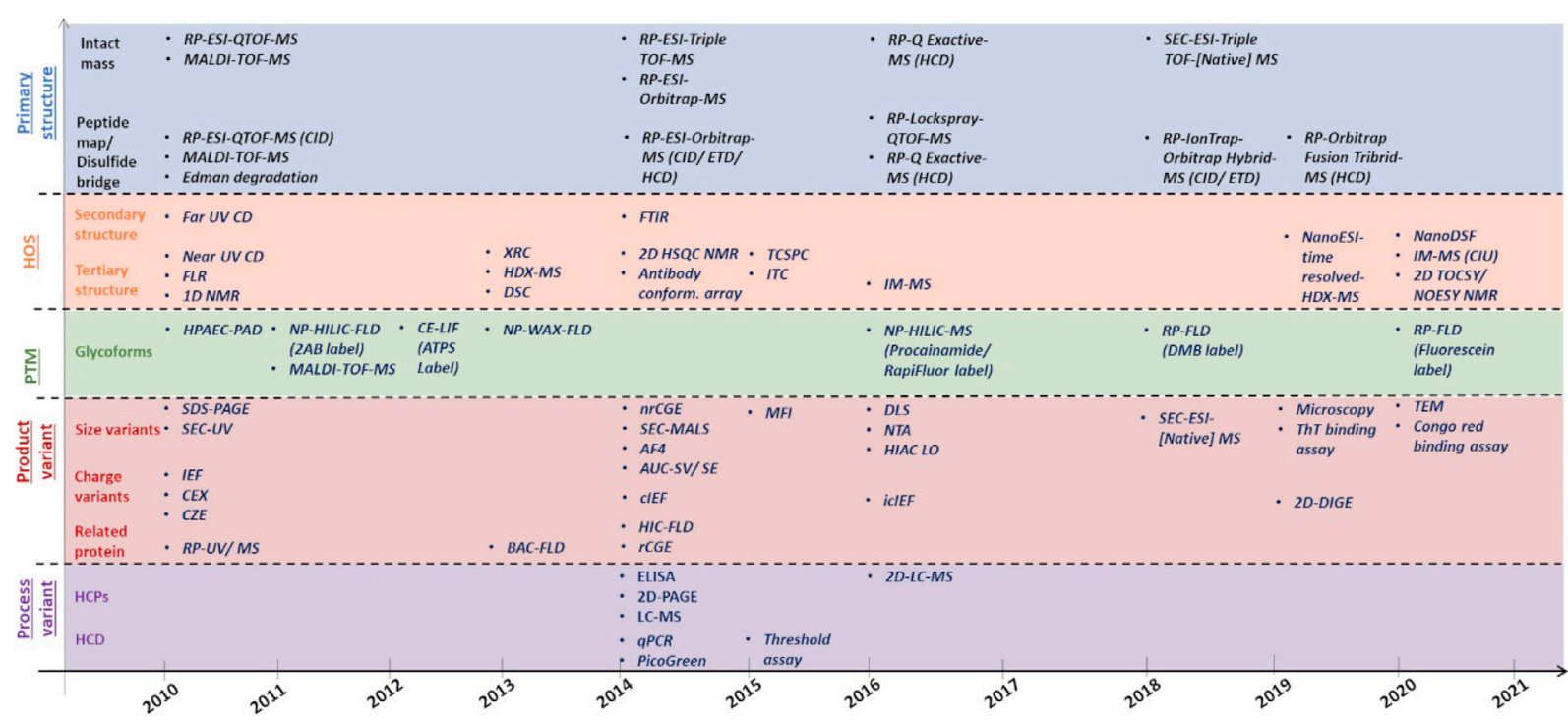

FIGURE 4 | Evolutionary timeline of analytical platforms used for different CQAs i.e., primary structure, HOS, glycosylation, product-related and process-related variant with respect to analytical biosimilarity assessment.

glycosylation and other PTMs can also be obtained through MS within a single analysis (Singleton, 2014). Over the years, MS platforms that have been featured in analytical similarity assessment publications for primary structure analysis include MALDI-TOF-MS, RP-ESI-QTOF-MS, RP-ESI-IonTrap/ Orbitrap/Q-Exactive-MS, LC-ESI-QTOF-[Native] MS (Figure 4, Supplementary Table S4).

For intact mass analysis, there have been recent advancements in developing LC-ESI-[Native] MS-based methods that offer an orthogonal alternative to traditional denaturing RP-ESI-MS where other LC modalities (such as SEC, HIC or IEX) are explored to determine intact mass with possible sequence variants under non-denaturing (native) conditions to identify biologically active species and monitor protein dynamics. SECESI-QTOF-MS has been employed in analytical biosimilarity assessment of biosimilar candidates of Amgen's bevacizumab (ABP 215) (Seo et al., 2018) and infliximab (ABP 710) (Saleem et al., 2020), Sun Pharma's rituximab (SB-02) (Singh et al., 2018) and Celtrion's infliximab (CT-P13) (Hermosilla et al., 2019) compared to the respective innovators. The advantage of SECMS over RP-MS is that the native structure is preserved, and so the information gained is not only a comparison on exact mass, but also of the higher-order structure of the intended biosimilar. In acknowledgment of this, a host of native MS-based analyses such as native-MS, ion mobility (IM)-MS, and time-resolved hydrogen-deuterium exchange (HDX)-MS have been employed to provide an unambiguous assessment of the structural, dynamic, and chemical biosimilarity for Apobiologix's bevacizumab biosimilar (Brown et al., 2019) (Supplementary Table S4).

For peptide mapping, the constant evolution of peptide ion fragmentation types, such as electron-transfer dissociation (ETD) and/or Higher-energy C-trap dissociation (HCD) versus collision-induced dissociation (CID) along with the use of LCQTOF, LC-Ion-Trap-Orbitrap and LC-Q-Exactive-Orbitrap MS has resulted in improvements in accurate identification and quantification of sequence variants and mutations. In two different studies, complete sequence coverage (100\%) was obtained after trypsin/Lys-C digestion by targeted and nontargeted comparison of the tryptic map for comparing trastuzumab biosimilars (Chen et al., 2013). Also, stable isotope labeling by amino acids in cell culture (SILAC) by dimethyl labeling [i.e., 2CH2 (rituximab) and 2CD2 (RNAimediated rituximab)] were used to detect sequence variants along with disulfide linkages, PTMs, and mutations (Li et al., 2013). LC-QTOF has been used for the complete amino acid sequence analysis of Celtrion's infliximab (Remsima) (Jung et al., 2014), trastuzumab (CT-P6) (Lee J. et al., 2018), rituximab (CT-P10) (Lee K. H. et al., 2018), Sun Pharma's rituximab (SB-02) (Singh et al., 2018) and Intas's pegfilgrastim (INTP5) (Shekhawat et al., 2019) biosimilars. Similarly, in recent years LC-Ion-Trap/Orbitrap Hybrid MS has been employed for characterization of certain biosimilars such as Amgen's bevacizumab (ABP 215) (Seo et al., 2018), rituximab (ABP 798) (Seo et al., 2020), infliximab (ABP 710) (Saleem et al., 2020), and Kyowa's adalimumab (Hulio ${ }^{\circledR}$ :FKB327) (Schreiber et al., 2020) biosimilars, and LC-Q-Exactive-OrbitrapMS was used for China's bevacizumab (BVZ-BC) (company name not indicated in associated publication) (Yu et al., 2020) and Amgen's eculizumab (ABP 959) (Hutterer et al., 2021) biosimilars, to determine similar amino acid sequence, PTM profiles, and disulfide linkages compared to the respective innovators.

RP-based peptide mapping has certain limitations including poor retention of small/hydrophilic peptides, limited peak capacity, and reduced sample throughput due to the need for 
re-equilibration between separations. This has largely been addressed through multi-dimensional LC platforms such as 2D-LC. Application of comprehensive two-dimensional liquid chromatography (2D-LC or LC $\times$ LC) as a tool for peptide mapping for trastuzumab has been demonstrated (Vanhoenacker et al., 2015). The method addresses identity, purity, and comparability of trastuzumab via three different combinations of LC $\times$ LC namely SCX, RP, and HILIC in the first dimension coupled with RP in the second dimension, respectively. In other studies, application of 2D-LC-MS has been demonstrated for antibody digests, with online-column digestion, followed by Orbitrap-MS for targeted peptide monitoring and chemometrics (Pérez-Robles et al., 2017; Shatat et al., 2018) (Supplementary Table S7).

Due to its sensitivity and dynamic range, more work is being done towards maximizing the capability of LC-MS-based formats through a more holistic characterization/comparability strategy including multiple levels of analysis (intact, subunit as well as peptides level). These multi-attribute methods (MAM) use a combination of high mass accuracy/high-resolution MS along with automated identification and relative quantification of the attributes (peptide mapping, glycopeptide, deamidation, and oxidation) with dedicated software. A head-to-head biosimilarity of trastuzumab and cetuximab with biosimilar candidates has been demonstrated at all levels including peptides and glycopeptides produced by enzymatic digestions (e.g., trypsin, Lys-C, Asp-N, pepsin) and analyzed on nanoLCQTOF-MS (Beck et al., 2015). MAM formats have also been demonstrated on formats such as LC-Orbitrap-MS. With respect to biosimilarity assessment, the new peak detection feature of the method has particular applicability as it automatizes the identification of new peaks in tested samples (Rogers et al., 2015, 2018) (Supplementary Table S7). The method has since been adopted in QC to release testing and MAM consortium has been formed to harmonize best practices and generate methodologies in the facilitation of the widespread integration of the MAM platform in QC labs (Millán-Martín et al., 2020). Recently, industry-wide inter-laboratory study (28 participating labs) using pre-digested samples of the NISTmAb RM 8671 and pre-defined experimental protocol has been conducted to test the robustness of MAM methods (Mouchahoir et al., 2021) (Supplementary Table S7). A version of the methods suitable for process development has been successfully implemented in three Sanofi sites with automatization of sample preparation as well as data interpretation (Song et al., 2021).

Other orthogonal platforms for primary structure assessment include MALDI-TOF-MS which offers a unique alternative to ESI-TOF-MS by producing less complicated spectra due to multiple charging and provides a significant tolerance against salts for fast and easy sample preparation. Few studies have reported the use of MALDI-TOF-MS for peptide mapping and disulfide bridging analysis of non-innovator versions, e.g., etanercept (AVG01) (Maity et al., 2011), TNFR-hyFc fusion protein (Lee et al., 2013), filgrastim (BK0023) (Crobu et al., 2014), and filgrastim (EP2006) (Sörgel et al., 2015) (Supplementary Table S4). In one of the study, chemometrics-based "nearness similarity index" was applied, as a mathematical comparison method applicable to complex mass spectrometric data, particularly in peptide maps obtained by MALDI-TOF-MS (Pérez-Robles et al., 2017) (Supplementary Table S7). The method was applied to identify changes in longterm stability assessment of infliximab and rituximab and should be applicable in biocomparability studies.

\subsubsection{Higher-Order Structure}

Higher-order structure (HOS) is an umbrella term for threedimensional (3D) conformations and includes multiple levels of structural hierarchies (i.e., secondary, tertiary and, quaternary). The concept of orthogonality is perhaps most celebrated for HOS characterization, since no one tool can map HOS in its entirety, hence multiple orthogonal tools are used for each level. Here, we have highlighted the evolution of orthogonality in published biosimilarity assessment studies (Figure 4) and discussed methods and techniques developed that have shown application towards biosimilarity assessment (Supplementary Table S7).

\subsubsection{Secondary Structure}

Initial biosimilarity assessment studies published on comparability of Eprex ${ }^{\circledR}$ (epoetin- $\alpha$ ), Nivestim ${ }^{\mathrm{TM}}$ and Zarzio ${ }^{\circledR}$ (filgrastim) to their respective reference products showed secondary structure comparability through overlay of far ultraviolet circular dichroism (far UV CD) spectra (Deechongkit et al., 2006; Skrlin et al., 2010; Srgel et al., 2010). Later, Fourier transform infrared (FTIR) spectroscopy has also been incorporated either instead of or more commonly as an orthogonal assessment technique (Jung et al., 2014; Liu et al., 2016). Portfolio of biosimilars where CD and/or FTIR has been used for evaluation of secondary structure biosimilarity to reference product is quite diverse and includes both $\mathrm{mAb}$ and non-mAb products (Supplementary Table S4).

Lately, deconvolution of CD spectra (Fazel et al., 2019; Hermosilla et al., 2020) and IR absorption spectra (1700-1,600 cm $\mathrm{cm}^{-1}$ ) (Lee et al., 2019; Shekhawat et al., 2019) using different software (K2D2, BeStSel, OriginPro, etc.) have been successfully used to quantitate secondary conformations (i.e., alpha-helix, beta-sheet, or random coil).

\subsubsection{Tertiary Structure}

Tertiary structures are 3D conformations. Near UV CD (250-300 nm) and fluorescence (FLR) spectroscopy have been traditionally the methods of choice for tertiary structure determination. In biosimilarity studies, these two techniques have been used either individually or together (Moro Pérez et al., 2019; Zhang et al., 2020). However, there have been limited studies involving the use of X-ray crystallography (XRC), a traditional technique for protein structural studies at the near-atomic level, as it works well only with proteins that can be crystallized, it requires expensive instrumentation, trained operators, and extensive time for analysis (Lerch et al., 2020). If we look at the evolution of HOS assessment in biosimilarity studies (Figure 4), the timeline is peppered with multiple orthogonal techniques such as single dimension NMR (Visser et al., 2013; Sörgel et al., 2015; Montacir et al., 2017), multi- 
dimension NMR (Shekhawat et al., 2019; Bor Tekdemir et al., 2020; Kovács et al., 2020), HDX-MS (Cho et al., 2016; Brokx et al., 2017; Brown et al., 2019), IM-MS (Fang et al., 2016; Montacir et al., 2017, 2018), antibody conformational array (Jung et al., 2014; Hong et al., 2017), aptamer-based enzyme linked aptasorbent assay (Wildner et al., 2019), and small angle X-ray scattering (SAXS) (Narvekar et al., 2020) (Supplementary Table S4). Of these, NMR has emerged as the new gold standard for HOS assessment with more than 10 published biosimilarity studies published with either $1 \mathrm{D}$, or $1 \mathrm{D}$ and $2 \mathrm{D}$ as a part of the analytical platform (Supplementary Table S4).

The popularity of NMR is also evident by the fact that by 2016, $15 \%$ of BLAs to USFDA included HDX-MS and NMR data for HOS characterization (USFDA, 2016). NMR is one of the highresolution biophysical techniques for obtaining information regarding protein structure, dynamics, and flexibility at the atomic level by mapping the individual atoms linkage with each other in the 3D space. However, its application for large molecules such as mAbs has been limited until recently. ${ }^{1} \mathrm{H}$ NMR has been implemented for HOS assessment, where pulsed-field gradient stimulated echo (PGSTE) experiment has been used to generate highly resolved spectra of intact $\mathrm{mAbs}$ in formulation buffers (Poppe et al., 2015) (Supplementary Table S7). Based on differences in the translational diffusion coefficients of molecules in the NMR sample, virtually all other undesired signals arising from water and excipients could be removed. The PROFILE method has since been implemented for similarity assessment studies with the application of chemometrics for statistical analysis of similarity.

Following 1D NMR, the applicability of 2D formats has also shown great promise in biosimilarity assessment, where two different isotopes have been used to generate each spectrum $\left({ }^{13} \mathrm{C},{ }^{1} \mathrm{H},{ }^{15} \mathrm{~N}\right.$ usually) and provide a series of ${ }^{1} \mathrm{H}$ or ${ }^{13} \mathrm{C}$ spectra, represented as a 2D diagram reflective of the HOS. Sophisticated sample preparation (radioactive labeling) required for NMR, along with the long acquisition time has been addressed in these studies along with characterization of different heterogeneities (charge variants, size, PTMs, glycosylation) present within the formulation. Seminal work in this field with respect to method validation and standardization for characterization of mAb-based modalities has been carried out by, or in association with NIST and made available as a series of publications (Arbogast et al., 2015, 2016, 2017; Brinson and Marino, 2019; Brinson et al., 2020; Sheen et al., 2020) (Supplementary Table S7). Recent studies have shown structural elucidation of mAbs at natural abundance via $2 \mathrm{D}$ -

${ }^{13} \mathrm{C}$ NMR in as little as $30 \mathrm{~min}$, along with evidence for high correlation of spectra from individual $\mathrm{Fab}$ and $\mathrm{Fc}$ fragments with intact mAb (Arbogast et al., 2015), as well as application of chemometrics for NMR spectral analysis and biosimilarity studies (both 1D and 2D-NMR) (Arbogast et al., 2016, 2017; Japelj et al., 2016; Chen et al., 2018; Brinson et al., 2020; Sheen et al., 2020) (Supplementary Table S7). In addition to HOS, NMR has also been shown as an orthogonal tool for the assessment of size variants in biotherapeutics (Patil et al., 2017; Joshi et al., 2021) (Supplementary Table S7). In the last couple of years, more work has been done on the identification of PTMs through NMR, although suitability for comparative analysis is yet to be demonstrated (Hinterholzer et al., 2019, 2020) (Supplementary Table S7).

Another orthogonal technique for dynamic HOS comparability is HDX-MS. It elucidates protein conformational dynamics, protein folding, and protein-ligand interactions. HDX-MS relies on the coupling of low-temperature UHPLC with the sensitivity and resolution of MS to determine the locations and rates of amide hydrogen deuterium uptake. In the last 5 years, there has been methodological advances w.r.t range of temperature required for HDX experiments, method reproducibility, significance testing, and application of HDX-MS for similarity assessments. This includes the optimization of HDX-MS methodology based on manual solid-phase extraction to allow a fast and simplified conformational analysis of proteins under pharmaceutically relevant formulation conditions as demonstrated on interferon- $\beta$ - $1 \mathrm{a}$ informulation samples (E. Nazari et al., 2016) (Supplementary Table S7).

Similar to the development of NMR methods for biopharmaceutical analysis, an interlaboratory method validation study to evaluate the reproducibility of HDX-MS has also been conducted (Hudgens et al., 2019) (Supplementary Table S7). The study determined the reproducibility of continuous-labeling, bottom-up HDX-MS measurements from the Fab fragment of NISTmAb reference material (PDB: 5K8A) in an inter-laboratory comparison study comprising 15 laboratories (Cummins et al., 2016) (Supplementary Table S7).

Harmonization of HDX-MS methodology for biopharmaceutical analysis has also led to studies exploring the application of statistics for fast and unbiased data analysis. For example, to eliminate subjectivity and reliably identify significant differences in HDX-MS measurements, null measurements were performed and compared the application of individual tests of significance with Bonferroni correction and globally estimated significance limit $(\Delta \mathrm{HX})$ to evaluate the risk (i.e., falsely classifying a difference as significant) and power (i.e., failing to classify a true difference as significant) associated with different statistical analysis approaches (Supplementary Table S7). Combining these two approaches, hybrid statistical analysis was suggested, based on volcano plots that simultaneously decreased the risk of false positives and retained superior power. However, as these methods are not directly applicable in a comparative analysis setup, the authors demonstrated adoption of a univariate two one-sided tests (TOST) equivalence testing method for biosimilarity assessment. Using this method, the group was able to statistically distinguish between $5 \%$ deglycosylated NISTmAb and its unmodified reference material (Hageman et al., 2021).

\subsubsection{Conformational Stability}

Conformational stability is measured as the change in enthalpy due to variation in physical and chemical properties of a molecule as a function of temperature and/or time. Thermal denaturation by variable temperature (VT)-CD has been traditionally used to 
study conformational stability as well as folding/unfolding mechanisms (Levy et al., 2014; Halim et al., 2018; Hermosilla et al., 2019) (Supplementary Table S4). Over the years, differential scanning calorimetry (DSC) has gained popularity as a fast and sensitive tool to measure thermodynamic stability and thermal unfolding pattern, where conformational changes are reflected as changes in characteristic transition/melting temperatures $(T \mathrm{~m})$ of one or multiple protein domains (Visser et al., 2013; Magnenat et al., 2017; Lee et al., 2019) (Supplementary Table S4). In recent times, time-correlated single-photon counting (TCSPC) is being used as an orthogonal technique to DSC to measure fluorescence lifetime distributions by the time-resolved intensity decay of protein (López-Morales et al., 2015; Mendoza-Macedo et al., 2016; Cerutti et al., 2019) (Supplementary Table S4). Other orthogonal tools include a fast, robust, low volume technique, i.e., nano differential scanning fluorimetry (nanoDSF) based on changes in intrinsic fluorescence upon thermal denaturation in a label-free fashion (Joshi et al., 2020; Wen et al., 2020) and IM-MS with collision-induced unfolding (CIU) (Kang et al., 2020b; 2020c) with limited applications so far (Supplementary Table S4).

\subsubsection{Glycosylation}

Glycosylation is an enzymatic PTM that occurs in proteins of eukaryotic origin (mAbs, Fc-fusion proteins, and others such as epoetin- $\alpha$ ). These exist in multiple glycoforms and exhibit complex micro-as well as macro-heterogeneity (Higel et al., 2016). A multi-level characterization strategy is generally adopted for glycan profiling, i.e., glycoprotein, glycopeptides, and released glycan levels that employs different LC-MS approaches with adaptations in sample preparation (reduction/ digestion/derivatization) and mode of chromatography [RP/ hydrophilic interaction chromatography (HILIC)] to suit the analyte size (intact/reduced/glycopeptide/released glycan) (Krull et al., 2020; Duivelshof et al., 2021) (Figure 4). Glycan characterization at the intact and reduced level follows a typical LC-MS routine workflow with minimal sample preparation. Released glycan analysis on the other hand is a fairly complex exercise with multiple steps in sample preparation followed by acquisition and detection through HILIC-FLD/MS. In earlier biosimilarity assessment publications, traditional labels, i.e., 2aminobenzoic acid (2AA), 2-aminobenzamide (2AB), or 4amino-N-(2-diethylaminoethyl) benzamide (procainamide) have been used (Lauber et al., 2015; Reusch et al., 2015) for sample preparation. The most common label that has been used in biosimilarity studies published so far is $2 \mathrm{AB}$ (Supplementary Table S4). In recent studies, use of novel commercial labels such as Glycoworks $^{\mathrm{TM}}$ or RapiFluor-MS ${ }^{\mathrm{TM}}$ with superior performance in terms of speed, sample preparation, fluorescence (FL) signal, and ionization efficiency have been used (Keser et al., 2018). Bioimilarity studies using RapiFluor-HILIC-FLD/MS for different biosimilar candidates include Celltrion's infliximab (Inflectra $^{\circledR}$ ) (Fang et al., 2016; Duivelshof et al., 2021), Shanghai Henlius's rituximab (HLX01) (Xu et al., 2019), and trastuzumab (HLX02) (Xie et al., 2020), Biocad's rituximab (Acellbia ${ }^{\circledR}$ ), where 32 glycoforms were detected by tandem MS, while only 13 glycoforms were detected by HILIC-FLD (Kang et al., 2020c), and China's ziv-aflibercept (Shen et al., 2021) (Supplementary Table S4).

For quantification of individual monosaccharides, Highperformance anion-exchange chromatography-pulsed amperometric detection (HPAEC-PAD) has been the preferred technique (Bruggink et al., 2005), followed by RP-FLD after labeling with 1, 2-diamino-4, 5-methylenedioxybenzenedihydrochloride (DMB) or fluorescein (Higel et al., 2013). Biosimilarity studies using HPAEC-PAD and RP-FLD have been detailed in the Supplementary Table S4.

For most chromatography-based analysis (irrespective of the attribute), Capillary Electrophoresis (CE) is often the popular orthogonal technique of choice. Recent advances in various $\mathrm{CE}$ modes have made it more user-friendly and versatile for glycan analysis. However, LC remains the preferred separation technique in similarity assessments. Examples of similarity assessments with orthogonal use of CZE (8-aminopyrene-1, 3, 6-trisulfonate, APTS labeling) and laser-induced fluorescence (LIF) detection to HILIC-FLD include China's etanercept (company name not mentioned in associated publication) (Tan et al., 2012) and Probiomed's trastuzumab (LópezMorales et al., 2015) and 10 different mAbs (Giorgetti et al., 2018). The applicability of capillary gel electrophoresis (CGE) for quantitative glycosimilarity assessment has been demonstrated for etanercept biosimilars (Borza et al., 2018) (Supplementary Table S4).

The high cost per analysis, long analysis time, and a need for sophisticated instrumentation as well as skill set required for data analysis have increased the need for orthogonal tools for glycan profiling. To address this, there has been an increase in the exploration of simpler glycan analysis formats utilizing spectroscopic tools such as RAMAN and FTIR wherein minimal sample preparation is required and chemometric methods are applied for data analysis. In one such study, RAMAN was used as a Process Analytical Technology (PAT) tool for monitoring glycosylation site occupancy in $\mathrm{CHO}$ cell cultures in real-time, indicating method developability for similarity assessment as a possibility in near future (Li et al., 2018) (Supplementary Table S7). In another recent study the utility of FTIR has been demonstrated for inter-batch or intersample comparison of monosaccharide profiles (Derenne et al., 2020) (Supplementary Table S7). The methodology is based on a statistical (PCA) comparison of FTIR spectra $(4,000$ and $600 \mathrm{~cm}^{-1}$ ) of buffer exchanged glyco-therapeutics (to remove noise from excipients). The group mapped the FTIR fingerprint of $17 \mathrm{mAbs}$ and found that it is not only sensitive to large differences such as the presence or absence of several monosaccharides but also to smaller modifications of the glycan and monosaccharide content. Another spectroscopic tool proposed for glycan profiling is NMR. In a proof of concept study, a "middle-down" NMR approach was conducted for identification of domain-specific glycosylation of mAbs without cleavage of the glycan moieties via sub-unit analysis of denatured Fc domain (Peng et al., 2018) (Supplementary Table S7). Chemical shift assignments from commercial standard glycans were obtained at ${ }^{13} \mathrm{C}$ natural abundance and allowed for 
unambiguous determination of the chemical structure, glycosidic linkage position, and anomeric configuration of each monosaccharide in the major $\mathrm{N}$-glycan scaffolds found in $\mathrm{mAb}$ molecules.

Another alternative/orthogonal glycan identification technique is lectin-microarray. Lectins are naturally occurring carbohydrate-binding proteins with affinities for specific sugar groups and due to this property, have found recent commercial application in glycan profiling for biotherapeutics. In a study, the utility as well as a high degree of orthogonality of commercial GlycoScope lectin microarray kit to three standard released glycan methods (HILIC-FLD of 2AA and 2AB labeling, HPAEC-PAD) have been demonstrated in an inter-lot comparability study (Cook et al., 2015) (Supplementary Table S7). The microarray platform comprised the microarray kit (microarray slides with Cy3-labelled goat anti-human-Fc antibody, IgG calibration standard, and components to prepare antibody exposure solution and bind/wash and block solutions) along with companion software for data interpretation and analysis.

Analysis of released glycans requires specific curated libraries for accurate annotation. Here, we would like to highlight two studies dealing with glycan data management, interpretation and analysis. The first study talks about the orthogonal application for structural annotation of $\mathrm{N}$-glycan in a capillary electropherogram using GUcal software (Jarvas et al., 2015) (Supplementary Table S7). The second study describes a novel software, namley $\mathrm{MoFi}$, which integrates hybrid MS data (intact and glycopeptide level) to assign glycan and PTMs to deconvoluted intact protein spectra (Skala et al., 2018) (Supplementary Table S7). The software first determines all monosaccharide/PTM compositions that are consistent with the residual masses derived from a deconvoluted spectrum of an intact glycoprotein, thereafter combining these primary annotations with a site-specific glycan library, generated through peptide mapping experiments. The software is unique in its data utilization approach and is capable of adding a new dimension of information to routine intact mass analysis, thereby making it more informative. The authors acknowledge the suitability of MoFi in GMP regulated biopharmaceutical analysis and it would indeed be interesting to evaluate its performance for biosimilarity assessment. Both $\mathrm{MoFi}$ and GUcal are freely available online.

\subsubsection{Product-Related Variants and Impurities}

Product-related variants and impurities corresponds to heterogeneities formed during bioprocess manufacturing, handling, and storage including size-based heterogeneities (aggregates, fragments, and sub-visible/visible particles), charge based heterogeneities (acidic and basic variants), and other product modifications (reduced, oxidized, glycated, misfolded proteins, etc.). Impurity profiling is a prerequisite during biosimilar development and specifications are set vis-à-vis the innovator for productrelated variants subjected to case-by-case evaluation depending on the nature of the variant (EMA, 1999).

\subsubsection{Aggregates/Fragments}

Aggregation/fragmentation occur due to protein unfolding of hydrophobic patches with environmental changes during various stages of the manufacturing process and may elicit immunogenic responses if present in significant amounts (Ratanji et al., 2014). The spectrum of aggregate size ranges between soluble aggregates to visible precipitates, depending upon exposure to various stresses (i.e., shear, thermal, chemical, freeze-thaw, etc.) and duration of exposure. Hence, its assessment involves the use of multiple orthogonal tools (Figure 4). Size exclusion chromatography (SEC)-UV is the method of choice. It can quantify soluble aggregates/fragments (1-100 nm) and offers rapid analysis, excellent resolution, robustness, and reproducibility. More recently SEC has been augmented with multi-angle light scattering (MALS) for measuring the size, i.e., molar mass and root-mean-square (RMS) radius (also called the radius of gyration, $R_{\mathrm{g}}$ ) of the different molecular species separated by SEC (Flores-Ortiz et al., 2014; Lee K. H. et al., 2018; Singh et al., 2018; Seo et al., 2020).

Protein loss due to stationary phase interactions and saltinduced aggregation/dissociation are common issues observed during SEC analysis. Hence, sedimentation velocity-analytical ultracentrifugation (SV-AUC), a matrix-free alternative to SEC, has been employed to quantitatively measure the size distribution. Researchers have proposed a validated AUC method and demonstrated its robustness as an orthogonal tool for similarity assessment of rituximab biosimilar product (Patil et al., 2020). However, AUC is not yet considered a technology that can be used for routine analysis, due to expensive instrumentation as well as challenging and time-intensive methods. While sodium dodecyl sulfate-polyacrylamide gel electrophoresis (SDS-PAGE) is still being used, it is qualitative in nature with limited sensitivity. CE-SDS, an automated version of SDS-PAGE in capillary format, is an orthogonal technique to SEC, particularly useful in quantifying fragments, partially reduced and non-glycosylated proteins (Shi et al., 2012; Wagner et al., 2020). Similarity studies with usage of SEC-UV/ MALS, SV-AUC and CE-SDS include biosimilar candidates of Celtrion's infliximab (Remsima ${ }^{\circledR}$ ) (Jung et al., 2014), trastuzumab (CT-P6) (Lee J. et al., 2018) and rituximab (CT-P10: Truxima ${ }^{\mathrm{TM}}$ ) (Lee K. H. et al., 2018), and Amgen's adalimumab (ABP 501) (Liu et al., 2016), bevacizumab (ABP 215) (Seo et al., 2018), infliximab (ABP 710) (Saleem et al., 2020), rituximab (ABP 798) (Seo et al., 2020) and eculizumab (ABP 959) (Hutterer et al., 2021) (Supplementary Table S4).

During SEC, insoluble aggregates/particles either elute out through the void volume or retain on the pre-column filter, hence needs to be analyzed using other techniques. These particles are categorized into sub-visible $(1-100 \mu \mathrm{m})$ and sub-micron $(100$ $\mathrm{nm}-1 \mu \mathrm{m})$ particles depending on particle size. Sub-visible particles are analyzed by light obscuration (LO) in high accuracy (HIAC) liquid particle counter and micro-flow imaging (MFI). LO, an indirect optical method, is used to measure particle size distribution (PSD) of particles $>10 \mu \mathrm{m}$ but underestimates smaller transparent particle populations, and cannot distinguish sub-populations (Narhi et al., 2009). 
Hence, more recently MFI is preferably used either singly or in conjunction with LO as an orthogonal technique for result validation (Sharma et al., 2010). Sub-micron particles are analyzed by dynamic light scattering (DLS) and field flow fractionation (FFF) or asymmetrical field flow fractionation (AF4). DLS is a semi-quantitative tool that determines PSD in the $1 \mathrm{~nm}-5 \mu \mathrm{m}$ range, but cannot measure accurate size (Ahrer et al., 2003). AF4 is a no matrix alternative tool orthogonal to SEC-UV/MALS, and DLS for aggregates $>1 \mathrm{~nm}$ which can be coupled with various detectors and enable analysis under native conditions (Contado, 2017). Few similarity studies have used all of the above multiple orthogonal platforms, i.e., LO, MFI, DLS and FFF in conjunction with SEC-UV/MALS, AUC, CE-SDS, for aggregate analysis. Examples include Amgen's adalimumab (ABP 501) (Liu et al., 2016), bevacizumab (ABP 215) (Seo et al., 2018), trastuzumab (ABP 980) (Hutterer et al., 2019), infliximab (ABP 710) (Saleem et al., 2020), and rituximab (ABP 798) (Seo et al., 2020) (Supplementary Table S4).

In addition to the established repertoire of tools above mentioned, DOSY-NMR has been demonstrated to be applicable for insulin and mAb-based formulations (Patil et al., 2017; Joshi et al., 2021). For mAbs, the relevance of DOSY-NMR for realistic hydrodynamic measurement has been demonstrated, where size estimations were found to be closer to computationally calculated radii of the published X-ray diffraction structures on Fab and Fc (Joshi et al., 2021) (Supplementary Table S7). Due to the highly heterogeneous nature of HMWs (in terms of shape and size), species-specific quantification is challenging (Hermosilla et al., 2020) (Supplementary Table S7). As a possible solution, researchers have developed a semi-automated electron microscopy (EM)based method that involves semi-automated, size-based clustering of different protein species from micrographs. Demonstrating its applicability on mAbs, the method was shown to automatically select a highly heterogeneous population of aggregates for a given sample and perform a size-based classification (number of aggregates of each species vs size of radius for the species) (Kumar et al., 2020) (Supplementary Table S7). Nanoparticle tracking analysis (NTA), a non-destructive, high resolving real-time monitoring technique to measure the number-based PSD of particles $>30 \mathrm{~nm}$, has found limited mention in similarity studies thus far (Moreno et al., 2016; Arvinte et al., 2019) (Supplementary Table S7).

\subsubsection{Charge Variants}

Charge variants are differently charged proteoforms formed in different colloidal matrices (i.e., culture media, in-process buffers, or formulation) during various stages of the manufacturing process. Charge variants are considered keyquality attributes (kQAs) and an ongoing scientific debate is prominent on its inclusion as a CQA (DBT, 2016; Singh et al., 2016). Over the years, cation exchange (CEX) chromatography has been the preferred tool for charged variant analysis as it offers rapid analysis, suitable resolution, robustness, and reproducibility (Joshi et al., 2015). Few similarity studies include Amgen's bevacizumab (ABP 215) (Seo et al., 2018), rituximab (ABP 798) (Seo et al., 2020) and infliximab (ABP
710) (Saleem et al., 2020). Similar to other chromatography based analysis, CE serves as a rapid, high-performance alternative tool orthogonal to CEX (Moritz et al., 2015) and has been employed in biosimilarity assessments such as for Sun Pharma's rhCG (SB005) (Thennati et al., 2018) and rituximab (SB-02) (Singh et al., 2018) (Supplementary Table S4). Further, the application of different modes of $\mathrm{CE}$ and hyphenation of CEX or CE with MS, have introduced more orthogonal tools to the analytical armory with respect to charge variant analysis (Gahoual et al., 2014; Haselberg et al., 2018). Capillary isoelectric focusing (cIEF), an extension to gel IEF in a capillary format, offers a pI based separation of charged species in a $\mathrm{pH}$ gradient in response to an electric field with higher resolution, lesser sample volume requirement, and faster sample analysis (Zhao and Chen, 2014; Suba et al., 2015). Image capillary isoelectric focusing (icIEF) allows the cIEF process to be "imaged" in real-time using whole-column imaging detection (WCID) technology. While, cIEF has been employed for charge profiling of biosimilar candidates of Amgen's adalimumab (ABP 501) (Liu et al., 2016) and bevacizumab (ABP 215) (Seo et al., 2018), and Probiomed S.A. de C.V.'s rituximab (Kikuzubam) (MirandaHernandez et al., 2015), etanercept (Infinitam ${ }^{\circledR}$ ) (MirandaHernández et al., 2016), trastuzumab-Probiomed (LópezMorales et al., 2015) and infliximab-Probiomed (VelascoVelázquez et al., 2017); examples of biosimilarity platforms with icIEF include Pfizer's infliximab (PF-06438179) (Derzi et al., 2016) and adalimumab (PF-06410293) (Derzi et al., 2020), Zhejiang Hisun's tocilizumab (HS628) (Miao et al., 2017), Samsung Bioepis's infliximab (SB2) (Hong et al., 2017) and adalimumab (SB5) (Lee et al., 2019), and Shanghai Henlius's rituximab (HLX01) (Xu et al., 2019), trastuzumab (HLX02) (Xie et al., 2020) and adalimumab (HLX03) (Zhang et al., 2020) (Supplementary Table S4).

Hyphenation of CEX/CE with MS either offline or via modifying the buffer system to use MS-compatible volatile salts (ammonium acetate/formate) has expanded the information gained by CEX/CE alone (Biacchi et al., 2015). The low flow operation of the microfluidic systems for CE-MS significantly boosts MS sensitivity and increased the dynamic range, even with sample amounts as low as $1 \mathrm{ng}$. Recently, 2 studies by Carillo et al., and Fussl et al., have demonstrated the application of commercially available microfluidic ZipChip microfluidic CE-MS technology for characterization of native charge variant profile complex mAbs such as cetuximab (Carillo et al., 2020; Fussl et al., 2020). Within the 1D-LC analysis format, there has been an increase in the development of MS-compatible CEX methods and direct online coupling of $\mathrm{CEX}$ to MS using volatile salt-based $\mathrm{pH}$ gradients, giving rise to Native CEX-MS. This has been demonstrated by multiple groups with variations in the stationary phase (weak and strong ion exchangers) and MS platforms (ESI-MS, IM-MS, and orbitrap) for trastuzumab, adalimumab, infliximab, bevacizumab, and cetuximab (Bailey et al., 2018; Füssl et al., 2018; Sankaran et al., 2018; Jaag et al., 2021; Murisier et al., 2021) (Supplementary Table S7). 


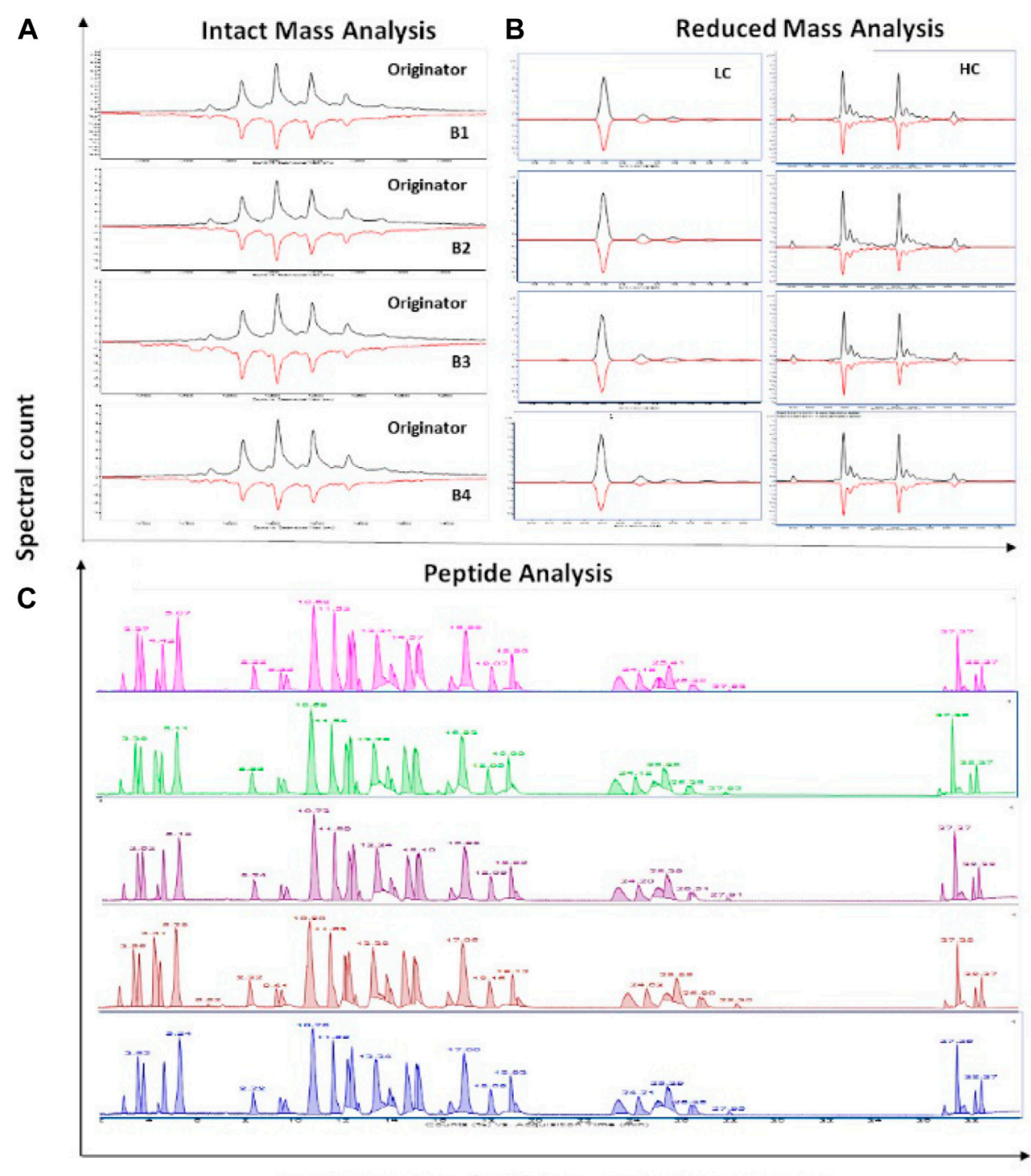

Acquisition time (min) Base peak chromatogram

FIGURE 5 | RP-LC-MS based primary structure biosimilarity assessment of trastuzumab originator and biosimilars as adapted from Joshi and Rathore, 2020. (A) mirror plot of Intact profile, (B) mirror plot of reduced profile and (C) stacked chromatograms of trastuzumab biosimilars compared with originator.

Multidimensional platforms such as 2D-LC with CEX in first dimension followed by an MS-compatible second dimension, i.e., RP (desalting improves peak capacity and MS compatibility) have also been incorporated in biosimilarity (Alvarez et al., 2011; Stoll et al., 2015) (Supplementary Table S7). More such applications for similarity assessment of biosimilars have also been shown for cetuximab, trastuzumab, and infliximab (Sorensen et al., 2016).

\subsubsection{Other Product Modifications}

Non-enzymatic PTMs include modifications such as oxidation, phosphorylation, sulfation, acetylation, methylation, and hydroxylation, that are formed during multiple stages of the manufacturing process. Liquid chromatography offers unparalleled selectivity towards the characterization of PTMs and the quantitation of related molecular variants and impurities. RPHPLC with UV/FLD is the preferred technique for quantifying oxidized and reduced species (Brokx et al., 2017; Bor Tekdemir et al., 2020). It has also been efficiently coupled with MS platforms for sitespecific identification and relative quantification (Lee K. H. et al., 2018; Saleem et al., 2020). Hydrophobic interaction chromatography (HIC) (Flores-Ortiz et al., 2014; Hassett et al., 2018) with UV/FLD for molecular variants, i.e., oxidized, deamidated with isomerization and/or succinimide formation, proteolytic fragments and misfolded species, and boronate affinity chromatography (BAC) (Visser et al., 2013; Singh et al., 2018) with FLD for glycated species have been less widely used for the separation of product-related variants (Supplementary Table S4). It must be noted that HIC is highly suitable to monitor oxidation, but for deamidation/isomerization, it is much less efficient than IEX. 


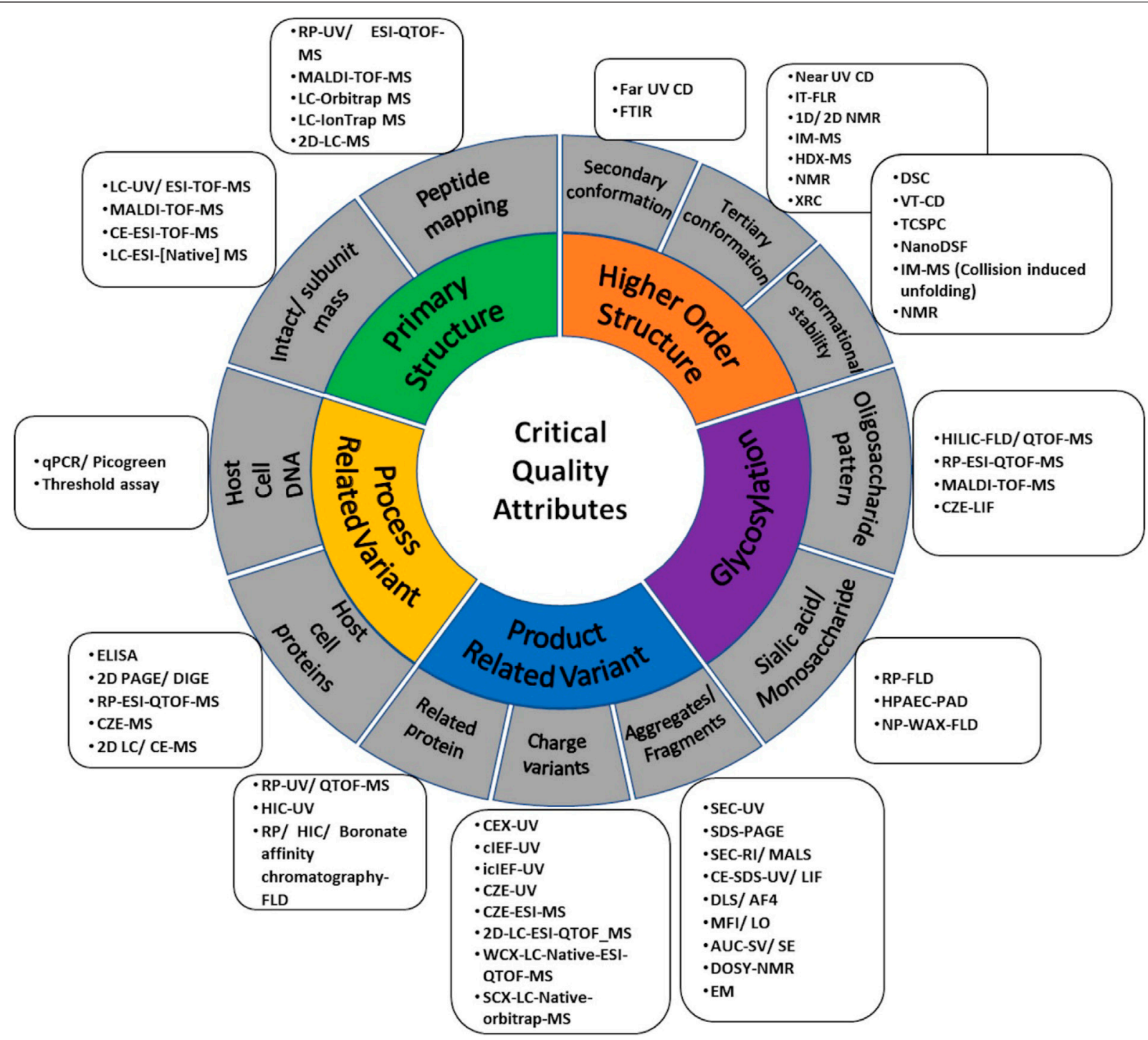

FIGURE 6 | A comprehensive map of orthogonal analytical platforms for different Critical Quality Attributes (CQAs) i.e., primary structure, Higher Order Structure (HOS), glycosylation, product-related and process-related variant used in analytical similarity assessment.

\subsubsection{Process-Related Variants}

Process-related variants, also called process residuals, include cell substrates, e.g., HCPs, HCD, cell culture, and downstream processing residuals. Enzyme-linked immunosorbent assay (ELISA) and real-time or quantitative PCR (qPCR using SYBR green, PicoGreen) have been consistently used as the method of choice for HCP and HCD detection and quantitation, respectively, in biosimilarity studies due to its high sensitivity, high throughput, and relative ease of use (Magalhaes et al., 2016; Xu et al., 2019; Xie et al., 2020) (Supplementary Table S4). Few publications have listed Threshold ${ }^{\mathrm{TM}}$ assays for HCD detection of filgrastim (EP2006; $\leq 200 \mathrm{pg} / \mathrm{mg}$ ) (Sörgel et al., 2015) and adalimumab (FKB327; <2 pg/mg) (Schreiber et al., 2020) biosimilars (Supplementary Table S4).

Specific to HCP analysis, orthogonal methods are coming into picture, since identification of individual HCPs is gaining importance in addition to measuring the overall amount of the HCPs Due to the complex nature of the HCP mixture, qualitative methods such as ELISA are being replaced in favor of proteomic techniques such as 2D-gel electrophoresis and LCMS/MS-based platforms. In two studies, three orthogonal methods, i.e., ELISA, 2D-PAGE/DIGE, and LC-MS/2D-LC$\mathrm{MS}^{\mathrm{E}}$ were used to identify, quantify and compare HCPs present in in-house filgrastim (Rathore and Bhambure, 2014) and Amgen's adalimumab (ABP 501) (Liu et al., 2016) biosimilars with respect to the innovators (Supplementary Table S4). Due to the limited separation efficiency of LCbased systems, 2D-LC (high-pH RP/low-pH RP)-IM-MS ${ }^{\mathrm{E}}$ platform have been explored for comparing $\mathrm{HCP}$ profiles between Celltrion's infliximab biosimilar (Inflectra) and Remicade ${ }^{\circledast}$ especially significant for co-eluting peptides (Fang et al., 2016) (Supplementary Table S4). Finally, orthogonal LC- 
MS platforms such as CZE-ESI-MS/MS have been successful in identification of a greater number of HCPs compared to LC-MS/ MS (Zhu et al., 2016; Kumar et al., 2021).

\subsubsection{Statistics in Analytical Biosimilarity Assessment}

While the analytical biosimilarity platforms have seen significant evolution over the years with respect to the techniques employed and orthogonal assessment of CQAs, data analysis has remained traditional for a large part, depending on comparison of information in the form of X-Y plots and charts. Recent conversations on statistical inference of biosimilarity have opened following USFDA's, now retracted draft guidance on "Statistical Approaches to Evaluate Analytical Similarity." The draft guidance suggested risk and criticality-based segregation of CQAs into tiers and the application of tier-based statistical tools for ascertaining confidence in similarity for a given analytical dataset (USFDA, 2017). Application of tier-based statistical assessment has thereafter been demonstrated in recent biosimilarity assessments of biosimilar candidates for Celltrion's trastuzumab (CT-P6) (Lee J. et al., 2018), Samsung Bioepis's adalimumab (SB5) (Lee et al., 2019) Shanghai Henlius's rituximab (HLX01) (Xu et al., 2019), adalimumab (HLX03) (Zhang et al., 2020), and Roche China's bevacizumab (BVZBC) (Yu et al., 2020) (Supplementary Table S4). Along the same line of thought, statistical alternatives to similarity evaluation in cases where multiple reference products exist (EU-approved and US-licensed) have been proposed such as the use of simultaneous confidence approach as a possible means to reconcile the biosimilarity between the reference products as using it as a whole in comparison to the intended biosimilar (Zheng et al., 2019) (Supplementary Table S7). Studies comparing test procedures using confidence intervals for recently developed methods as well as other previously developed methods applied for demonstrating analytical biosimilarity have also been published (Burdick et al., 2017; Wang and Chow, 2017; Quiroz et al., 2019; Chen and Hsiao, 2020) (Supplementary Table S7). Comparative signature diagrams (CSDs) has been explored as an orthogonal visualization technique for analytical data sets in the form of colored contour plots (Kim et al., 2016) (Supplementary Table S7). However, these studies do not address orthogonal ways to analyze the raw data. As far as orthogonal strategies for raw data evaluation go, the application of multivariate data analysis (MVDA) techniques such as principal component analysis (PCA) has been applied to spectroscopy data from NMR and MS towards an unbiased spectral comparison of products (Arbogast et al., 2017; Chen et al., 2018; Shatat et al., 2018; Hassan et al., 2019; Brinson et al., 2020; Wang et al., 2020) (Supplementary Table S7). What remains yet unexplored, is the application of advanced statistics towards a holistic, multi-technique, multi-attribute biosimilarity assessment that also incorporates the impact of criticality of a CQA on relevance of a given data. In addition, application of statistics towards a scoring strategy for biosimilars has also yet to be demonstrated. Some examples of biosimilar scoring strategies limited to single instrument data have been published in recent times. These include a study where multivariate data analysis method based on JMP ${ }^{\circledR}$ software
(SAS Institute Inc.) was developed to assess the glycosylation pattern similarity of antibody candidates from different conditions and scoring was done based on specific distance between the biosimilar and the reference product ( $\mathrm{Xu}$ et al., 2021) (Supplementary Table S7). Another, single attribute-based scoring strategy has been used to list the different glycosylation related CQAs (gCQAs) and then describe calculations for establishing two different similarity scores, namely profile similarity score and compositional similarity score. The mean of these two scores has been defined as the final Glycosimilarity Index (GI) (Szekrenyes et al., 2020) (Supplementary Table S7).

\section{CONCLUSION}

Biosimilars are targeted to be an affordable alternative for expensive innovator biologics. However, reaching the goal of affordability without compromising with quality is challenging and requires a collaborative effort from manufacturers and regulators, guided by subject matter experts. For emerging biosimilar manufacturers and pharmaceutical manufactures that are expanding their offerings in the biosimilar domain, there is a steep learning curve with regards to successful manufacturing of biosimilars as translational learnings from the pharmaceutical sector are limited. Therefore, in the interest of affordability, it is important to build an informative corpus of common knowledge regarding all aspects of biosimilar development. This review is a step in that direction.

Over the years, as blockbuster drugs reach patent expiry, there has been a steady increase in the number of biosimilar approvals in all the major jurisdictions, especially for mAbs. There has also been an increase in published biosimilarity assessment studies. However, it does not yet commensurate with the rate of approvals and more such assessments need to be published through peerreviewed pathways. The number of approvals as well as published assessments is likely to go up as global guidelines on interchangeability evolve and there is more market acceptance for these products. The data presented in peer-reviewed similarity assessment studies are representative of the total data generated during a similarity exercise and thus a good indicator of the percolation of new technologies from R\&D stage to incorporation in the analytical platform to increase complementarity or orthogonality. Putting together all the tools that have either been used in similarity assessments or for which application towards similarity has been indicated, a comprehensive map of analytical platform, including orthogonal tools, has been built as an outcome of the literature survey done in this review (Figure 6).

As there is a cost attached with the incorporation of any new technology in the similarity assessment platform, common/well established tools and techniques that can be applied across the CQA spectrum are likely to be preferred. So far, the evolution of similarity assessment platforms reflects a growing acceptance of hyphenated platforms (separation $\mathrm{x}$ detection) with MS being the prevalent end-point detector. This is followed by advancements in spectroscopy, such as the inclusion of NMR for whole molecule analysis. 
Recent technological advancements with respect to the application of 2D-NMR, multidimensional chromatography, HDX-MS, and spectroscopy in the characterization of CQAs with several publications on method standardization of these techniques towards similarity assessment have populated the scholastic space. However, to facilitate affordability, future similarity assessment exercises need to be more lightweight with respect to the number of tools and more diverse and information-intensive with respect to characterization. A possible solution seems to emerge in the form of MAMs. Indeed, there is a growing trend towards establishing multiattribute monitoring and analysis methods for process control and purity analysis. Current MAMs are MS-based and applicable on digested proteins and MAM developments in whole molecule assessments in formulation conditions via LC-MS or spectroscopy platforms are a welcome move for similarity assessments.

We hope that the repositories provided as tables in the main text as well as Supplementary Information acts as a useful go to source for biopharmaceutical scientists, academicians, interested regulators as well as manufacturers, for the purpose of designing analytical similarity assessment platforms, decision making on tools to invest in, common methodologies to be adopted and also for general understanding of biosimilar and similarity landscape.

\section{AUTHOR CONTRIBUTIONS}

NN: Methodology, Investigation, Analysis, Writing- original draft. SJ: Methodology, Investigation, Analysis, Writing-

\section{REFERENCES}

Ahrer, K., Buchacher, A., Iberer, G., Josic, D., and Jungbauer, A. (2003). Analysis of Aggregates of Human Immunoglobulin $G$ Using Size-Exclusion Chromatography, Static and Dynamic Light Scattering. J. Chromatogr. A 1009, 89-96. doi:10.1016/S0021-9673(03)00433-3

Alsamil, A. M., Giezen, T. J., Egberts, T. C., Leufkens, H. G., Vulto, A. G., van der Plas, M. R., et al. (2020). Reporting of Quality Attributes in Scientific Publications Presenting Biosimilarity Assessments of (Intended) Biosimilars: a Systematic Literature Review. Eur. J. Pharm. Sci. 154, 105501. doi:10.1016/j. ejps.2020.105501

Alvarez, M., Tremintin, G., Wang, J., Eng, M., Kao, Y.-H., Jeong, J., et al. (2011). On-line Characterization of Monoclonal Antibody Variants by Liquid Chromatography-Mass Spectrometry Operating in a Two-Dimensional Format. Anal. Biochem. 419, 17-25. doi:10.1016/j.ab.2011.07.033

Amgen (2021). Amgen Reports Fourth Quarter and Full Year 2020 Financial Results. New York: P R Newswire. Available at: https://www.prnewswire.com/news-releases/ amgen-reports-fourth-quarter-and-full-year-2020-financial-results-301220622.html (Accessed January 6, 2022).

Arbogast, L. W., Brinson, R. G., Formolo, T., Hoopes, J. T., and Marino, J. P. (2016). 2D 1HN, 15N Correlated NMR Methods at Natural Abundance for Obtaining Structural Maps and Statistical Comparability of Monoclonal Antibodies. Pharm. Res. 33, 462-475. doi:10.1007/s11095-015-1802-3

Arbogast, L. W., Brinson, R. G., and Marino, J. P. (2015). Mapping Monoclonal Antibody Structure by 2D 13C NMR at Natural Abundance. Anal. Chem. 87, 3556-3561. doi:10.1021/ac504804m

Arbogast, L. W., Delaglio, F., Schiel, J. E., and Marino, J. P. (2017). Multivariate Analysis of Two-Dimensional 1H, 13C Methyl NMR Spectra of Monoclonal Antibody Therapeutics to Facilitate Assessment of Higher Order Structure. Anal. Chem. 89, 11839-11845. doi:10.1021/acs. analchem.7b03571 original draft. DG: review and editing. AR: Conceptualization, Supervision, Project administration, Writing-review and editing, Funding acquisition and Resources.

\section{FUNDING}

This work was funded by the Center of Excellence for Biopharmaceutical Technology grant under the Department of Biotechnology, Government of India (BT/COE/34/ SP15097/2015). Agilent was not involved in the study design, collection, analysis, interpretation of data, the writing of this article or the decision to submit it for publication.

\section{ACKNOWLEDGMENTS}

The authors would also like to thank Agilent Technologies India Private Limited for funding this research as part of its corporate social responsibility initiative.

\section{SUPPLEMENTARY MATERIAL}

The Supplementary Material for this article can be found online at: https://www.frontiersin.org/articles/10.3389/fbioe.2022.832059/ full\#supplementary-material

Arvinte, T., Palais, C., Poirier, E., Cudd, A., Rajendran, S., Brokx, S., et al. (2019). Part 1: Physicochemical Characterization of Bevacizumab in Undiluted $25 \mathrm{mg} /$ $\mathrm{mL}$ Drug Product Solutions: Comparison of Originator with a Biosimilar Candidate. J. Pharm. Biomed. Anal. 175, 112742. doi:10.1016/j.jpba.2019.06.039

Bailey, A. O., Han, G., Phung, W., Gazis, P., Sutton, J., Josephs, J. L., et al. (2018). Charge Variant Native Mass Spectrometry Benefits Mass Precision and Dynamic Range of Monoclonal Antibody Intact Mass Analysis. MAbs 10, 1214-1225. doi:10.1080/19420862.2018.1521131

Beck, A., Debaene, F., Diemer, H., Wagner-Rousset, E., Colas, O., DorsselaerVan, A. V., et al. (2015). Cutting-edge Mass Spectrometry Characterization of Originator, Biosimilar and Biobetter Antibodies. J. Mass. Spectrom. 50, 285-297. doi:10.1002/jms.3554

Biacchi, M., Gahoual, R., Said, N., Beck, A., Leize-Wagner, E., and François, Y.-N. (2015). Glycoform Separation and Characterization of Cetuximab Variants by Middle-Up Off-Line Capillary Zone Electrophoresis-UV/Electrospray Ionization-MS. Anal. Chem. 87, 6240-6250. doi:10.1021/acs.analchem.5b00928

Bor Tekdemir, Z., Seckin, A. I., Kacar, T., Yilmaz, E., and Bekiroglu, S. (2020). Evaluation of Structural, Biological, and Functional Similarity of Biosimilar Granulocyte Colony Stimulating Factor to its Reference Product. Pharm. Res. 37. doi:10.1007/s11095-020-02932-7

Borza, B., Szigeti, M., Szekrenyes, A., Hajba, L., and Guttman, A. (2018). Glycosimilarity Assessment of Biotherapeutics 1: Quantitative Comparison of the $\mathrm{N}$-glycosylation of the Innovator and a Biosimilar Version of Etanercept. J. Pharm. Biomed. Anal. 153, 182-185. doi:10.1016/j.jpba.2018.02.021

Brinson, R. G., Elliott, K. W., Arbogast, L. W., Sheen, D. A., Giddens, J. P., Marino, J. P., et al. (2020). Principal Component Analysis for Automated Classification of 2D Spectra and Interferograms of Protein Therapeutics: Influence of Noise, Reconstruction Details, and Data Preparation. J. Biomol. NMR 74, 643-656. doi:10.1007/s10858-020-00332-y

Brinson, R. G., and Marino, J. P. (2019). 2D J-Correlated Proton NMR Experiments for Structural Fingerprinting of Biotherapeutics. J. Magn. Reson. 307, 106581. doi:10.1016/j.jmr.2019.106581 
Brokx, S., Scrocchi, L., Shah, N., and Dowd, J. (2017). A Demonstration of Analytical Similarity Comparing a Proposed Biosimilar Pegfilgrastim and Reference Pegfilgrastim. Biologicals 48, 28-38. doi:10.1016/j.biologicals.2017. 06.001

Brown, K. A., Rajendran, S., Dowd, J., and Wilson, D. J. (2019). Rapid Characterization of Structural and Functional Similarity for a Candidate Bevacizumab (Avastin) Biosimilar Using a Multipronged Massspectrometry-based Approach. Drug Test. Anal. 11, 1207-1217. doi:10.1002/ dta.2609

Bruggink, C., Maurer, R., Herrmann, H., Cavalli, S., and Hoefler, F. (2005). Analysis of Carbohydrates by Anion Exchange Chromatography and Mass Spectrometry. J. Chromatogr. A 1085, 104-109. doi:10.1016/j.chroma.2005. 03.108

Burdick, R., Coffey, T., Gutka, H., Gratzl, G., Conlon, H. D., Huang, C.-T., et al. (2017). Statistical Approaches to Assess Biosimilarity from Analytical Data. AAPS J. 19, 4-14. doi:10.1208/s12248-016-9968-0

Canada (2016). Guidance Document: Information and Submission Requirements for Biosimilar Biologic Drugs.

Carillo, S., Jakes, C., and Bones, J. (2020). In-depth Analysis of Monoclonal Antibodies Using Microfluidic Capillary Electrophoresis and Native Mass Spectrometry. J. Pharm. Biomed. Anal. 185, 113218. doi:10.1016/j.jpba.2020. 113218

CDSCO (2020). List of New Drugs (R-DNA Origin) Approved for Manufacture and Marketing in India. Available at: https://www.cdsco.gov.in/opencms/opencms/ en/biologicals/rDNA/(Accessed June 9, 2021).

Cerutti, M. L., Pesce, A., Bès, C., and Seigelchifer, M. (2019). Physicochemical and Biological Characterization of RTXM83, a New Rituximab Biosimilar. BioDrugs 33, 307-319. doi:10.1007/s40259-019-00349-2

Chen, C., and Hsiao, C. F. (2020). Use of Tolerance Intervals for Assessing Biosimilarity. Stat. Med. 39, 3806-3822. doi:10.1002/SIM.8695

Chen, K., Park, J., Li, F., Patil, S. M., and Keire, D. A. (2018). Chemometric Methods to Quantify 1D and 2D NMR Spectral Differences Among Similar Protein Therapeutics. AAPS PharmSciTech 19, 1011-1019. doi:10.1208/s12249-017-0911-1

Chen, S.-L., Wu, S.-L., Huang, L.-J., Huang, J.-B., and Chen, S.-H. (2013). A Global Comparability Approach for Biosimilar Monoclonal Antibodies Using LCTandem MS Based Proteomics. J. Pharm. Biomed. Anal. 80, 126-135. doi:10. 1016/j.jpba.2013.02.040

CHMP (2014). Committee for Medicinal Products for Human Use (CHMP): Guideline on Similar Biological Medicinal Products - Revision 1. Available at: www.ema.europa.eu/contact (Accessed July 1, 2021).

CHMP (2005). Committee for Medicinal Products for Human Use (CHMP): Guideline on Similar Biological Medicinal Products.

Cho, I. H., Lee, N., Song, D., Jung, S. Y., Bou-Assaf, G., Sosic, Z., et al. (2016). Evaluation of the Structural, Physicochemical, and Biological Characteristics of SB4, a Biosimilar of Etanercept. MAbs 8, 1136-1155. doi:10.1080/19420862. 2016.1193659

Contado, C. (2017). Field Flow Fractionation Techniques to Explore the "NanoWorld". Anal. Bioanal. Chem. 409, 2501-2518. doi:10.1007/s00216-017-0180-6

Cook, M. C., Kaldas, S. J., Muradia, G., Rosu-Myles, M., and Kunkel, J. P. (2015). Comparison of Orthogonal Chromatographic and Lectin-Affinity Microarray Methods for Glycan Profiling of a Therapeutic Monoclonal Antibody. J. Chromatogr. B 997, 162-178. doi:10.1016/j.jchromb.2015.05.035

Crobu, D., Spinetti, G., Schrepfer, R., Tonon, G., Jotti, G. S., Onali, P., et al. (2014). Preclinical and Clinical Phase I Studies of a New Recombinant Filgrastim (BK0023) in Comparison with Neupogen ${ }^{\circledR}$. BMC Pharmacol. Toxicol. 15, 7. doi:10.1186/2050-6511-15-7

Cummins, D. J., Espada, A., Novick, S. J., Molina-Martin, M., Stites, R. E., Espinosa, J. F., et al. (2016). Two-Site Evaluation of the Repeatability and Precision of an Automated Dual-Column Hydrogen/Deuterium Exchange Mass Spectrometry Platform. Anal. Chem. 88, 6607-6614. doi:10.1021/acs.analchem.6b01650

DBT (2016). CDSCO: Guidelines on Similar Biologics: Regulatory Requirements for Marketing Authorization in India. Available at: https://nib.gov.in/NIBDBT2016.pdf (Accessed June 9, 2021).

Deechongkit, S., Aoki, K. H., Park, S. S., and Kerwin, B. A. (2006). Biophysical Comparability of the Same Protein from Different Manufacturers: A Case Study Using Epoetin Alfa from Epogen and Eprex. J. Pharm. Sci. 95, 1931-1943. doi:10.1002/jps.20649
Derbyshire, M., and Shina, S. (2019). Patent Expiry Dates for Biologicals: 2018 Update. Gabi J. 8, 24-31. doi:10.5639/gabij.2019.0801.003

Derenne, A., Derfoufi, K.-M., Cowper, B., Delporte, C., and Goormaghtigh, E. (2020). FTIR Spectroscopy as an Analytical Tool to Compare Glycosylation in Therapeutic Monoclonal Antibodies. Analytica Chim. Acta 1112, 62-71. doi:10. 1016/j.aca.2020.03.038

Derzi, M., Johnson, T. R., Shoieb, A. M., Conlon, H. D., Sharpe, P., Saati, A., et al. (2016). Nonclinical Evaluation of PF-06438179: A Potential Biosimilar to Remicade (Infliximab). Adv. Ther. 33, 1964-1982. doi:10.1007/s12325-0160403-9

Derzi, M., Shoieb, A. M., Ripp, S. L., Finch, G. L., Lorello, L. G., O’Neil, S. P., et al. (2020). Comparative Nonclinical Assessments of the Biosimilar PF-06410293 and Originator Adalimumab. Regul. Toxicol. Pharmacol. 112, 104587. doi:10. 1016/j.yrtph.2020.104587

Duivelshof, B. L., Denorme, S., Sandra, K., Liu, X., Beck, A., Lauber, M. A., et al. (2021). Quantitative N-Glycan Profiling of Therapeutic Monoclonal Antibodies Performed by Middle-Up Level HILIC-HRMS Analysis. Pharmaceutics 13 (13), 1744. doi:10.3390/PHARMACEUTICS13111744

EMA (1996). ICH Topic Q5C: Quality of Biotechnological Products: Stability Testing of Biotechnological/Biological Products. Available at: https://www.ema.europa.eu/en/ documents/scientific-guideline/ich-topic-q-5-c-quality-biotechnological-productsstability-testing-biotechnological/biological-products_en.pdf (Accessed June 9, 2021).

EMA (2005). ICH Topic Q5E: Comparability of Biotechnological/Biological Products.

EMA (1999). ICH Topic Q6B Specifications: Test Procedures and Acceptance Criteria for Biotechnological/Biological Products. Available at: https://www.ema.europa.eu/ en/documents/scientific-guideline/ich-q-6-b-test-procedures-acceptance-criteriabiotechnological/biological-products-step-5_en.pdf (Accessed June 9, 2021).

EMA (2020). Medicines: European Medicines Agency. Available at: https://www.ema. europa.eu/en/medicines/search_api_aggregation_ema_medicine_types/field_ema_ med_biosimilar (Accessed June 9, 2021).

E. Nazari, Z. Z., van de Weert, M., Bou-Assaf, G., Houde, D., Weiskopf, A., and D. Rand, K. K. (2016). Rapid Conformational Analysis of Protein Drugs in Formulation by Hydrogen/Deuterium Exchange Mass Spectrometry. J. Pharm. Sci. 105, 3269-3277. doi:10.1016/j.xphs.2016.07.006

Eon-Duval, A., Broly, H., and Gleixner, R. (2012). Quality Attributes of Recombinant Therapeutic Proteins: an Assessment of Impact on Safety and Efficacy as Part of a Quality by Design Development Approach. Biotechnol. Prog. 28, 608-622. doi:10.1002/BTPR.1548

Fang, J., Doneanu, C., Alley, W. R., Yu, Y. Q., Beck, A., and Chen, W. (2016). Advanced Assessment of the Physicochemical Characteristics of Remicade and Inflectra by Sensitive LC/MS Techniques. MAbs 8, 1021-1034. doi:10.1080/ 19420862.2016.1193661

Fazel, R., Guan, Y., Vaziri, B., Krisp, C., Heikaus, L., Saadati, A., et al. (2019). Structural and In Vitro Functional Comparability Analysis of Altebrel, a Proposed Etanercept Biosimilar: Focus on Primary Sequence and Glycosylation. Pharmaceuticals 12, 14. doi:10.3390/ph12010014

Fekete, S., Gassner, A.-L., Rudaz, S., Schappler, J., and Guillarme, D. (2013). Analytical Strategies for the Characterization of Therapeutic Monoclonal Antibodies. Trac Trends Anal. Chem. 42, 74-83. doi:10.1016/j.trac.2012. 09.012

Fekete, S., Guillarme, D., Sandra, P., and Sandra, K. (2016). Chromatographic, Electrophoretic, and Mass Spectrometric Methods for the Analytical Characterization of Protein Biopharmaceuticals. Anal. Chem. 88, 480-507. doi:10.1021/acs.analchem.5b04561

Flores-Ortiz, L. F., Campos-García, V. R., Perdomo-Abúndez, F. C., Pérez, N. O., and Medina-Rivero, E. (2014). Physicochemical Properties of Rituximab. J. Liquid Chromatogr. Relat. Tech. 37, 1438-1452. doi:10.1080/10826076. 2013.794738

Füssl, F., Cook, K., Scheffler, K., Farrell, A., Mittermayr, S., and Bones, J. (2018). Charge Variant Analysis of Monoclonal Antibodies Using Direct Coupled pH Gradient Cation Exchange Chromatography to HighResolution Native Mass Spectrometry. Anal. Chem. 90, 4669-4676. doi:10.1021/acs.analchem.7b05241

Füssl, F., Trappe, A., Carillo, S., Jakes, C., and Bones, J. (2020). Comparative Elucidation of Cetuximab Heterogeneity on the Intact Protein Level by Cation 
Exchange Chromatography and Capillary Electrophoresis Coupled to Mass Spectrometry. Anal. Chem. 92, 5431-5438. doi:10.1021/acs.analchem.0c00185

GaBI (2021). Copy Biologicals Approved in China. Available at: https://www.gabionline. net/biosimilars/general/copy-biologicals-approved-in-china (Accessed July 17, 2021).

GaBI (2020). Non-originator Biologicals Approved in Russia. Available at: https:// www.gabionline.net/biosimilars/general/Non-originator-biologicals-approvedin-Russia (Accessed July 17, 2021).

GaBI (2019). Similar Biotherapeutic Products Approved and Marketed in Latin America. Available at: https://gabionline.net/biosimilars/general/Similarbiotherapeutic-products-approved-and-marketed-in-Latin-America (Accessed July 17, 2021).

Gahoual, R., Biacchi, M., Chicher, J., Kuhn, L., Hammann, P., Beck, A., et al. (2014). Monoclonal Antibodies Biosimilarity Assessment Using Transient Isotachophoresis Capillary Zone Electrophoresis-Tandem Mass Spectrometry. MAbs 6, 1464-1473. doi:10.4161/mabs.36305

Gherghescu, I., and Delgado-Charro, M. B. (2020). The Biosimilar Landscape: An Overview of Regulatory Approvals by the EMA and FDA. Pharmaceutics 13 (13), 48. doi:10.3390/PHARMACEUTICS13010048

Giorgetti, J., D’Atri, V., Canonge, J., Lechner, A., Guillarme, D., Colas, O., et al. (2018). Monoclonal Antibody N-Glycosylation Profiling Using Capillary Electrophoresis - Mass Spectrometry: Assessment and Method Validation. Talanta 178, 530-537. doi:10.1016/j.talanta.2017.09.083

Global (2018). Report on Global Biologics Market Size, Market Share, Application Analysis, Regional Outlook, Growth Trends, Key Players, Competitive Strategies and Forecasts, 2018 to 2026. Available at: https://www.researchandmarkets. com/reports/4564281/global-biologics-market-size-market-share (Accessed April 27, 2021).

Hageman, T. S., Wrigley, M. S., and Weis, D. D. (2021). Statistical Equivalence Testing of Higher-Order Protein Structures with Differential Hydrogen Exchange-Mass Spectrometry (HX-MS). Anal. Chem. 93, 6980-6988. doi:10. 1021/acs.analchem.0c05279

Halim, L. A., Márquez, M., Maas-Bakker, R. F., Castañeda-Hernández, G., Jiskoot, W., and Schellekens, H. (2018). Quality Comparison of Biosimilar and Copy Filgrastim Products with the Innovator Product. Pharm. Res. 35. doi:10.1007/ s11095-018-2491-5

Haselberg, R., De Vijlder, T., Heukers, R., Smit, M. J., Romijn, E. P., Somsen, G. W., et al. (2018). Heterogeneity Assessment of Antibody-Derived Therapeutics at the Intact and Middle-Up Level by Low-Flow Sheathless Capillary Electrophoresis-Mass Spectrometry. Analytica Chim. Acta 1044, 181-190. doi:10.1016/j.aca.2018.08.024

Hassan, L. A., Shatat, S. M., Eltanany, B. M., Al-Ghobashy, M. A., and Abbas, S. S. (2019). Stability and Biosimilarity Assessment of Infliximab Using an Orthogonal Testing Protocol and Statistically-Guided Interpretation of Peptide Mapping. Anal. Methods 11, 3198-3211. doi:10.1039/ c9ay00903e

Hassett, B., Scheinberg, M., Castañeda-Hernández, G., Li, M., Rao, U. R. K., Singh, E., et al. (2018). Variability of Intended Copies for Etanercept (Enbrel): Data on Multiple Batches of Seven Products. MAbs 10, 166-176. doi:10.1080/19420862. 2017.1387346

Health (2021). Department of Health: Which Biosimilar Medicines Are Available in Australia? Available at: https://www1.health.gov.au/internet/main/publishing. nsf/Content/biosimilar-which-medicines-are-available-in-australia (Accessed June 9, 2021).

Hermosilla, J., Pérez-Robles, R., Salmerón-García, A., Casares, S., Cabeza, J., Bones, J., et al. (2020). Comprehensive Biophysical and Functional Study of ZivAflibercept: Characterization and Forced Degradation. Sci. Rep. 10, 1-13. doi:10.1038/s41598-020-59465-7

Hermosilla, J., Sánchez-Martín, R., Pérez-Robles, R., Salmerón-García, A., Casares, S., Cabeza, J., et al. (2019). Comparative Stability Studies of Different Infliximab and Biosimilar CT-P13 Clinical Solutions by Combined Use of Physicochemical Analytical Techniques and Enzyme-Linked Immunosorbent Assay (ELISA). BioDrugs 33, 193-205. doi:10.1007/s40259-019-00342-9

Higel, F., Demelbauer, U., Seidl, A., Friess, W., and Sörgel, F. (2013). Reversedphase Liquid-Chromatographic Mass Spectrometric N-Glycan Analysis of Biopharmaceuticals. Anal. Bioanal. Chem. 405 (405), 2481-2493. doi:10. 1007/S00216-012-6690-3
Higel, F., Seidl, A., Sörgel, F., and Friess, W. (2016). N-glycosylation Heterogeneity and the Influence on Structure, Function and Pharmacokinetics of Monoclonal Antibodies and Fc Fusion Proteins. Eur. J. Pharmaceutics Biopharmaceutics 100, 94-100. doi:10.1016/j.ejpb.2016.01.005

Hinterholzer, A., Stanojlovic, V., Cabrele, C., and Schubert, M. (2019). Unambiguous Identification of Pyroglutamate in Full-Length Biopharmaceutical Monoclonal Antibodies by NMR Spectroscopy. Anal. Chem. 91, 14299-14305. doi:10.1021/acs.analchem.9b02513

Hinterholzer, A., Stanojlovic, V., Regl, C., Huber, C. G., Cabrele, C., and Schubert, M. (2020). Identification and Quantification of Oxidation Products in FullLength Biotherapeutic Antibodies by NMR Spectroscopy. Anal. Chem. 92, 9666-9673. doi:10.1021/acs.analchem.0c00965

Hong, J., Lee, Y., Lee, C., Eo, S., Kim, S., Lee, N., et al. (2017). Physicochemical and Biological Characterization of SB2, a Biosimilar of Remicade (Infliximab). MAbs 9, 365-383. doi:10.1080/19420862.2016.1264550

Hudgens, J. W., Gallagher, E. S., Karageorgos, I., Anderson, K. W., Filliben, J. J., Huang, R. Y.-C., et al. (2019). Interlaboratory Comparison of Hydrogen-Deuterium Exchange Mass Spectrometry Measurements of the Fab Fragment of NISTmAb. Anal. Chem. 91, 7336-7345. doi:10.1021/ACS.ANALCHEM.9B01100

Hutterer, K. M., Ip, A., Kuhns, S., Cao, S., Wikström, M., and Liu, J. (2021). Analytical Similarity Assessment of ABP 959 in Comparison with Eculizumab Reference Product. BioDrugs 35, 563-577. doi:10.1007/S40259-021-00492-9

Hutterer, K. M., Polozova, A., Kuhns, S., McBride, H. J., Cao, X., and Liu, J. (2019). Assessing Analytical and Functional Similarity of Proposed Amgen Biosimilar ABP 980 to Trastuzumab. BioDrugs 33, 321-333. doi:10.1007/s40259-01900350-9

Ishii-Watabe, A., and Kuwabara, T. (2019). Biosimilarity Assessment of Biosimilar Therapeutic Monoclonal Antibodies. Drug Metab. Pharmacokinet. 34, 64-70. doi:10.1016/j.dmpk.2018.11.004

Jaag, S., Shirokikh, M., and Lämmerhofer, M. (2021). Charge Variant Analysis of Protein-Based Biopharmaceuticals Using Two-Dimensional Liquid Chromatography Hyphenated to Mass Spectrometry. J. Chromatogr. A 1636, 461786. doi:10.1016/j.chroma.2020.461786

Jacobs, I., Ewesuedo, R., Lula, S., and Zacharchuk, C. (2017). Biosimilars for the Treatment of Cancer: A Systematic Review of Published Evidence. BioDrugs 31, 1-36. doi:10.1007/s40259-016-0207-0

Jacobs, I., Petersel, D., Shane, L. G., Ng, C.-K., Kirchhoff, C., Finch, G., et al. (2016). Monoclonal Antibody and Fusion Protein Biosimilars across Therapeutic Areas: A Systematic Review of Published Evidence. BioDrugs 30 (30), 489-523. doi:10.1007/S40259-016-0199-9

Japelj, B., Ilc, G., Marušič, J., Senčar, J., Kuzman, D., and Plavec, J. (2016). Biosimilar Structural Comparability Assessment by NMR: From Small Proteins to Monoclonal Antibodies. Sci. Rep. 6, 1-12. doi:10.1038/srep32201

Jarvas, G., Szigeti, M., and Guttman, A. (2015). GUcal: An Integrated Application for Capillary Electrophoresis Based Glycan Analysis. Electrophoresis 36, 3094-3096. doi:10.1002/elps.201500397

Joshi, S., Khatri, L. R., Kumar, A., and Rathore, A. S. (2021). Monitoring Size and Oligomeric-State Distribution of Therapeutic mAbs by NMR and DLS: Trastuzumab as a Case Study. J. Pharm. Biomed. Anal. 195, 113841. doi:10. 1016/j.jpba.2020.113841

Joshi, S., Maharana, C., and Rathore, A. S. (2020). An Application of Nano Differential Scanning Fluorimetry for Higher Order Structure Assessment between $\mathrm{mAb}$ Originator and Biosimilars: Trastuzumab and Rituximab as Case Studies. J. Pharm. Biomed. Anal. 186, 113270. doi:10.1016/j.jpba.2020. 113270

Joshi, S., and Rathore, A. S. (2020). Assessment of Structural and Functional Comparability of Biosimilar Products: Trastuzumab as a Case Study. BioDrugs 34, 209-223. doi:10.1007/s40259-020-00404-3

Joshi, V., Kumar, V., and Rathore, A. S. (2015). Rapid Analysis of Charge Variants of Monoclonal Antibodies Using Non-linear Salt Gradient in Cation-Exchange High Performance Liquid Chromatography. J. Chromatogr. A 1406, 175-185. doi:10.1016/j.chroma.2015.06.015

Jung, S. K., Lee, K. H., Jeon, J. W., Lee, J. W., Kwon, B. O., Kim, Y. J., et al. (2014). Physicochemical Characterization of Remsima. MAbs 6, 1163-1177. doi:10. 4161/mabs.32221

Kang, H.-N., Thorpe, R., Knezevic, I., Blades, C. D. R. Z., Casas Levano, M., Chew, J. Y., et al. (2020a). The Regulatory Landscape of Biosimilars: WHO Efforts and 
Progress Made from 2009 to 2019. Biologicals 65, 1-9. doi:10.1016/j.biologicals. 2020.02.005

Kang, H. N., Thorpe, R., Knezevic, I., Casas Levano, M., Chilufya, M. B., Chirachanakul, P., et al. (2021). Regulatory Challenges with Biosimilars: an Update from 20 Countries. Ann. N.Y. Acad. Sci. 1491, 42-59. doi:10.1111/nyas. 14522

Kang, J., Halseth, T., Vallejo, D., Najafabadi, Z. I., Sen, K. I., Ford, M., et al. (2020b). Assessment of Biosimilarity under Native and Heat-Stressed Conditions: Rituximab, Bevacizumab, and Trastuzumab Originators and Biosimilars. Anal. Bioanal. Chem. 412, 763-775. doi:10.1007/s00216-019-02298-9

Kang, J., Kim, S. Y., Vallejo, D., Hageman, T. S., White, D. R., Benet, A., et al. (2020c). Multifaceted Assessment of Rituximab Biosimilarity: The Impact of Glycan Microheterogeneity on Fc Function. Eur. J. Pharmaceutics Biopharmaceutics 146, 111-124. doi:10.1016/j.ejpb.2019.12.003

Keser, T., Pavić, T., Lauc, G., and Gornik, O. (2018). Comparison of 2aminobenzamide, Procainamide and RapiFluor-MS as Derivatizing Agents for High-Throughput HILIC-UPLC-FLR-MS N-Glycan Analysis. Front. Chem. 6, 324. doi:10.3389/fchem.2018.00324

Kim, J. H., Joshi, S. B., Esfandiary, R., Iyer, V., Bishop, S. M., Volkin, D. B., et al. (2016). Improved Comparative Signature Diagrams to Evaluate Similarity of Storage Stability Profiles of Different IgG1 mAbs. J. Pharm. Sci. 105, 1028-1035. doi:10.1016/j.xphs.2016.01.008

Kovács, P., Schäfer, T., Háda, V., Hevér, H., Klingelhöfer, S., Nebel, M., et al. (2020). Comparative Physicochemical and Biological Characterisation of the Similar Biological Medicinal Product Teriparatide and its Reference Medicinal Product. BioDrugs 34, 65-75. doi:10.1007/s40259-019-00386-x

Krull, I., Rathore, A. S., and Budholiya, N. (2020). A Review of Recent Developments in Analytical Characterization of Glycosylation in Therapeutic Proteins. Cranbury, NJ: LCGC North Am., 30-37. Available at: https://www.chromatographyonline. $\mathrm{com} /$ view/review-recent-developments-analytical-characterization-glycosylationtherapeutic-proteins (Accessed June 9, 2021).

Kumar, M., Pant, A., Bansal, R., Pandey, A., Gomes, J., Khare, K., et al. (2020). Electron Microscopy-Based Semi-automated Characterization of Aggregation in Monoclonal Antibody Products. Comput. Struct. Biotechnol. J. 18, 1458-1465. doi:10.1016/j.csbj.2020.06.009

Kumar, R., Shah, R. L., Ahmad, S., and Rathore, A. S. (2021). Harnessing the Power of Electrophoresis and Chromatography: Offline Coupling of Reverse Phase Liquid Chromatography-capillary Zone Electrophoresis-tandem Mass Spectrometry for Analysis of Host Cell Proteins in Monoclonal Antibody Producing CHO Cell Line. Electrophoresis 42, 735-741. doi:10.1002/elps. 202000252

Lauber, M. A., Yu, Y.-Q., Brousmiche, D. W., Hua, Z., Koza, S. M., Magnelli, P., et al. (2015). Rapid Preparation of Released N-Glycans for HILIC Analysis Using a Labeling Reagent that Facilitates Sensitive Fluorescence and ESI-MS Detection. Anal. Chem. 87, 5401-5409. doi:10.1021/acs. analchem.5b00758

Lee, J.-H., Yeo, J., Park, H. S., Sung, G., Lee, S. H., Yang, S. H., et al. (2013). Biochemical Characterization of a New Recombinant TNF Receptor-hyFc Fusion Protein Expressed in CHO Cells. Protein Expr. Purif. 87, 17-26. doi:10.1016/j.pep.2012.09.001

Lee, J., Kang, H. A., Bae, J. S., Kim, K. D., Lee, K. H., Lim, K. J., et al. (2018a). Evaluation of Analytical Similarity between Trastuzumab Biosimilar CT-P6 and Reference Product Using Statistical Analyses. MAbs 10, 547-571. doi:10. 1080/19420862.2018.1440170

Lee, K. H., Lee, J., Bae, J. S., Kim, Y. J., Kang, H. A., Kim, S. H., et al. (2018b). Analytical Similarity Assessment of Rituximab Biosimilar CT-P10 to Reference Medicinal Product. MAbs 10, 380-396. doi:10.1080/19420862.2018.1433976

Lee, N., Lee, J. J., Yang, H., Baek, S., Kim, S., Kim, S., et al. (2019). Evaluation of Similar Quality Attribute Characteristics in SB5 and Reference Product of Adalimumab. MAbs 11, 129-144. doi:10.1080/19420862.2018.1530920

Lerch, T. F., Sharpe, P., Mayclin, S. J., Edwards, T. E., Polleck, S., Rouse, J. C., et al. (2020). Crystal Structures of PF-06438179/GP1111, an Infliximab Biosimilar. BioDrugs 34, 77-87. doi:10.1007/s40259-019-00390-1

Levy, M. J., Gucinski, A. C., Sommers, C. D., Ghasriani, H., Wang, B., Keire, D. A., et al. (2014). Analytical Techniques and Bioactivity Assays to Compare the Structure and Function of Filgrastim (Granulocyte-colony Stimulating Factor) Therapeutics from Different Manufacturers. Anal. Bioanal. Chem. 406, 6559-6567. doi:10.1007/s00216-013-7469-x
Li, C., Rossomando, A., Wu, S.-L., and Karger, B. L. (2013). Comparability Analysis of Anti-CD20 Commercial (Rituximab) and RNAi-Mediated Fucosylated Antibodies by Two LC-MS Approaches. MAbs 5, 565-575. doi:10.4161/ mabs. 24814

Li, M.-Y., Ebel, B., Paris, C., Chauchard, F., Guedon, E., and Marc, A. (2018). Realtime Monitoring of Antibody Glycosylation Site Occupancy by In Situ Raman Spectroscopy during Bioreactor CHO Cell Cultures. Biotechnol. Prog. 34, 486-493. doi:10.1002/btpr.2604

Liu, J., Eris, T., Li, C., Cao, S., and Kuhns, S. (2016). Assessing Analytical Similarity of Proposed Amgen Biosimilar ABP 501 to Adalimumab. BioDrugs 30, 321-338. doi:10.1007/s40259-016-0184-3

López-Morales, C. A., Miranda-Hernández, M. P., Juárez-Bayardo, L. C., RamírezIbáñez, N. D., Romero-Díaz, A. J., Piña-Lara, N., et al. (2015). Physicochemical and Biological Characterization of a Biosimilar Trastuzumab. Biomed. Res. Int. 2015, 1-10. doi:10.1155/2015/427235

Magalhaes, V., Mantovani, M., Caruso, C., Facchini, F., Pascon, R., and Cagnacci, P. (2016). Physicochemical and Biological Comparison of the First Brazilian Biosimilar Filgrastim with its Reference Product. Bs 6, 45-60. doi:10.2147/bs. s107898

Magnenat, L., Palmese, A., Fremaux, C., D’Amici, F., Terlizzese, M., Rossi, M., et al. (2017). Demonstration of Physicochemical and Functional Similarity between the Proposed Biosimilar Adalimumab MSB11022 and Humira. MAbs 9, 127-139. doi:10.1080/19420862.2016.1259046

Maity, S., Ullanat, R., Lahiri, S., Shekar, S., Sodhan, G., Vyas, A., et al. (2011). A Non-innovator Version of Etanercept for Treatment of Arthritis. Biologicals 39, 384-395. doi:10.1016/j.biologicals.2011.08.014

Mendoza-Macedo, K., Romero-Díaz, A. J., Miranda-Hernández, M. P., CamposGarcía, V. R., Ramírez-Ibañez, N. D., Juárez-Bayardo, L. C., et al. (2016). Characterization and Comparability of Biosimilars: A Filgrastim Case of Study and Regulatory Perspectives for Latin America. Electron. J. Biotechnol. 24, 63-69. doi:10.1016/j.ejbt.2016.10.003

MFDS (2020). Biosimilar: Minisry of Food and Drug Safety. Available at: https:// www.mfds.go.kr/eng/wpge/m_37/de0110241001.do (Accessed June 9, 2021).

Miao, S., Fan, L., Zhao, L., Ding, D., Liu, X., Wang, H., et al. (2017). Physicochemical and Biological Characterization of the Proposed Biosimilar Tocilizumab. Biomed. Res. Int. 2017, 1-13. doi:10.1155/2017/4926168

Millán-Martín, S., Jakes, C., Carillo, S., Buchanan, T., Guender, M., Kristensen, D. B., et al. (2020). Inter-laboratory Study of an Optimised Peptide Mapping Workflow Using Automated Trypsin Digestion for Monitoring Monoclonal Antibody Product Quality Attributes. Anal. Bioanal. Chem. 412, 6833-6848. doi:10.1007/s00216-020-02809-z

Miranda-Hernández, M. P., López-Morales, C. A., Perdomo-Abúndez, F. C., Salazar-Flores, R. D., Ramírez-Ibanez, N. D., Pérez, N. O., et al. (2016). New Alternatives for Autoimmune Disease Treatments: Physicochemical and Clinical Comparability of Biosimilar Etanercept. J. Immunol. Res. 2016, 1-9. doi:10.1155/2016/9697080

Miranda-Hernández, M. P., López-Morales, C. A., Ramírez-Ibáñez, N. D., PiñaLara, N., Pérez, N. O., Molina-Pérez, A., et al. (2015). Assessment of Physicochemical Properties of Rituximab Related to its Immunomodulatory Activity. J. Immunol. Res. 2015, 1-10. doi:10.1155/2015/910763

Montacir, O., Montacir, H., Eravci, M., Springer, A., Hinderlich, S., Saadati, A., et al. (2017). Comparability Study of Rituximab Originator and Follow-On Biopharmaceutical. J. Pharm. Biomed. Anal. 140, 239-251. doi:10.1016/j.jpba. 2017.03.029

Montacir, O., Montacir, H., Springer, A., Hinderlich, S., Mahboudi, F., Saadati, A., et al. (2018). Physicochemical Characterization, Glycosylation Pattern and Biosimilarity Assessment of the Fusion Protein Etanercept. Protein J. 37, 164-179. doi:10.1007/s10930-018-9757-y

Moorkens, E., Vulto, A. G., and Huys, I. (2020). An Overview of Patents on Therapeutic Monoclonal Antibodies in Europe: Are They a Hurdle to Biosimilar Market Entry? mAbs 12, 1743517. doi:10.1080/19420862.2020. 1743517

Moreno, M. R., Tabitha, T. S., Nirmal, J., Radhakrishnan, K., Yee, C. H., Lim, S., et al. (2016). Study of Stability and Biophysical Characterization of Ranibizumab and Aflibercept. Eur. J. Pharmaceutics Biopharmaceutics 108, 156-167. doi:10.1016/j.ejpb.2016.09.003

Moritz, B., Schnaible, V., Kiessig, S., Heyne, A., Wild, M., Finkler, C., et al. (2015). Evaluation of Capillary Zone Electrophoresis for Charge Heterogeneity Testing 
of Monoclonal Antibodies. J. Chromatogr. B 983-984, 101-110. doi:10.1016/j. jchromb.2014.12.024

Moro Pérez, L., Rodríguez Taño, A. d. l. C., Martín Márquez, L. R., Gómez Pérez, J. A., Valle Garay, A., and Blanco Santana, R. (2019). Rodríguez Taño, A. de la C., Martín Márquez, L. R., Gómez Pérez, J. A., Garay, A. V., and Santana, R. BConformational characterization of a novel anti-HER2 candidate antibody. PLoS ONE 14, e0215442. doi:10.1371/journal.pone.0215442

Mouchahoir, T., Schiel, J. E., Rogers, R., Heckert, A., Place, B. J., Ammerman, A., et al. (2021). New Peak Detection Performance Metrics from the MAM Consortium Interlaboratory Study. J. Am. Soc. Mass. Spectrom. 32, 913-928. doi:10.1021/JASMS.0C00415

Murisier, A., Duivelshof, B. L., Fekete, S., Bourquin, J., Schmudlach, A., Lauber, M. A., et al. (2021). Towards a Simple On-Line Coupling of Ion Exchange Chromatography and Native Mass Spectrometry for the Detailed Characterization of Monoclonal Antibodies. J. Chromatogr. A 1655, 462499. doi:10.1016/j.chroma.2021.462499

Narhi, L., Jiang, Y., Cao, S., Benedek, K., and Shnek, D. (2009). A Critical Review of Analytical Methods for Subvisible and Visible Particles. Cpb 10, 373-381. doi:10.2174/138920109788488905

Narvekar, A., Gawali, S. L., Hassan, P. A., Jain, R., and Dandekar, P. (2020). pH Dependent Aggregation and Conformation Changes of Rituximab Using SAXS and its Comparison with the Standard Regulatory Approach of Biophysical Characterization. Int. J. Biol. Macromolecules 164, 3084-3097. doi:10.1016/j. ijbiomac.2020.08.148

Nerkar, S., Darandale, M., and Sumant, O. (2021). Erythropoietin Drugs Market by Product Type (Epoetin-Alfa, Epoetin-Beta, and Darbepoetin-Alfa, Others) and Application (Hematology, Kidney Disorder, Cancer, Others): Global Opportunity Analysis and Industry Forecast, 2021-2028. Pune, India: Allied Mark. Res. Available at: https://www.alliedmarketresearch.com/erythropoietin-market (Accessed January 6, 2022).

NPRA (2021). Biosimilars Approved. Available at: https://www.npra.gov.my/ index.php/en/informationen/new-products-indication/biosimilars-approved. html (Accessed July 17, 2021).

Nupur, N., Chhabra, N., Dash, R., and Rathore, A. S. (2018). Assessment of Structural and Functional Similarity of Biosimilar Products: Rituximab as a Case Study. MAbs 10, 143-158. doi:10.1080/19420862.2017.1402996

Nupur, N., Singh, S. K., Narula, G., and Rathore, A. S. (2016). Assessing Analytical Comparability of Biosimilars: GCSF as a Case Study. J. Chromatogr. B 1032, 165-171. doi:10.1016/j.jchromb.2016.05.027

Ortiz-Prado, E., Ponce-Zea, J., Vasconez, J. E., Castillo, D., Checa-Jaramilloz, D. C., Rodríguez-Burneo, N., et al. (2020). Current Trends for Biosimilars in the Latin American Market. Gabi J. 9, 64-74. doi:10.5639/gabij.2020. 0902.011

Pategou, J. (2020). Africa's Biosimilar Landscape Outlook Current Challenges. Available at: https://www.biosimilardevelopment.com/doc/africa-sbiosimilar-landscape-outlook-current-challenges-0001 (Accessed July 1, 2021).

Patil, S. M., Keire, D. A., and Chen, K. (2017). Comparison of NMR and Dynamic Light Scattering for Measuring Diffusion Coefficients of Formulated Insulin: Implications for Particle Size Distribution Measurements in Drug Products. AAPS J. 19, 1760-1766. doi:10.1208/s12248-017-0127-z

Patil, S. M., Nguyen, J., Keire, D. A., and Chen, K. (2020). Sedimentation Velocity Analytical Ultracentrifugation Analysis of Marketed Rituximab Drug Product Size Distribution. Pharm. Res. 37 (37), 1-14. doi:10.1007/ S11095-020-02961-2

Peng, J., Patil, S. M., Keire, D. A., and Chen, K. (2018). Chemical Structure and Composition of Major Glycans Covalently Linked to Therapeutic Monoclonal Antibodies by Middle-Down Nuclear Magnetic Resonance. Anal. Chem. 90, 11016-11024. doi:10.1021/acs.analchem.8b02637

Pérez-Robles, R., Navas, N., Medina-Rodríguez, S., and Cuadros-Rodríguez, L. (2017). Method for the Comparison of Complex Matrix Assisted Laser Desorption Ionization-Time of Flight Mass Spectra. Stability of Therapeutical Monoclonal Antibodies. Chemometrics Intell. Lab. Syst. 170, 58-67. doi:10.1016/j.chemolab.2017.09.008

PMDA (2020). List of Approved Products: Pharmaceuticals and Medical Devices Agency. Available at: https://www.pmda.go.jp/english/review-services/reviews/ approved-information/drugs/0002.html (Accessed June 9, 2021).

Poppe, L., Jordan, J. B., Rogers, G., and Schnier, P. D. (2015). On the Analytical Superiority of 1D NMR for Fingerprinting the Higher Order Structure of
Protein Therapeutics Compared to Multidimensional NMR Methods. Anal. Chem. 87, 5539-5545. doi:10.1021/acs.analchem.5b00950

Quiroz, J., Montes, R., Shi, H., and Roychoudhury, S. (2019). A Comparative Study of Confidence Intervals to Assess Biosimilarity from Analytical Data. Pharm. Stat. 18, 316-328. doi:10.1002/pst.1925

Ratanji, K. D., Derrick, J. P., Dearman, R. J., and Kimber, I. (2014). Immunogenicity of Therapeutic Proteins: Influence of Aggregation. J. Immunotoxicology 11, 99-109. doi:10.3109/1547691X.2013.821564

Rathore, A. S., and Bhambure, R. (2014). Establishing Analytical Comparability for "Biosimilars": Filgrastim as a Case Study. Anal. Bioanal. Chem. 406, 6569-6576. doi:10.1007/s00216-014-7887-4

Rathore, A. S., and Bhargava, A. (2020). Biosimilars in Developed Economies: Overview, Status, and Regulatory Considerations. Regul. Toxicol. Pharmacol. 110, 104525. doi:10.1016/j.yrtph.2019.104525

Rathore, A. S., and Bhargava, A. (2021a). Regulatory Considerations in Biosimilars: Asia pacific Regions. Prep. Biochem. Biotechnol. 51, 1-8. doi:10.1080/10826068. 2020.1815061

Rathore, A. S., and Bhargava, A. (2021b). Regulatory Considerations in Biosimilars: Latin America Region. Prep. Biochem. Biotechnol. 51, 201-206. doi:10.1080/ 10826068.2021.1876729

Rathore, A. S., and Bhargava, A. (2021c). Regulatory Considerations in Biosimilars: Middle East and Africa Regions. Prep. Biochem. Biotechnol. 51, 731-737. doi:10. 1080/10826068.2021.1959346

Ratih, R., Asmari, M., Abdel-Megied, A. M., Elbarbry, F., and El Deeb, S. (2021). Biosimilars: Review of Regulatory, Manufacturing, Analytical Aspects and beyond. Microchemical J. 165, 106143. doi:10.1016/j.microc.2021.106143

Reusch, D., Haberger, M., Maier, B., Maier, M., Kloseck, R., Zimmermann, B., et al. (2015). Comparison of Methods for the Analysis of Therapeutic Immunoglobulin G Fc-Glycosylation Profiles-Part 1: Separation-Based Methods. MAbs 7, 167-179. doi:10.4161/19420862.2014.986000

Rogers, R. S., Abernathy, M., Richardson, D. D., Rouse, J. C., Sperry, J. B., Swann, P., et al. (2018). A View on the Importance of "Multi-Attribute Method" for Measuring Purity of Biopharmaceuticals and Improving Overall Control Strategy. Aaps J. 20. doi:10.1208/s12248-017-0168-3

Rogers, R. S., Nightlinger, N. S., Livingston, B., Campbell, P., Bailey, R., and Balland, A. (2015). Development of a Quantitative Mass Spectrometry Multi-Attribute Method for Characterization, Quality Control Testing and Disposition of Biologics. MAbs 7, 881-890. doi:10.1080/19420862.2015.1069454

Safdar, A., Butt, M. H., Ahmad, A., and Zaman, M. (2021). Progress in Oncology Biosimilars till 2020: Scrutinizing Comparative Studies of Biosimilar Monoclonal Antibodies. J. Oncol. Pharm. Pract. 27, 107815522110160-107815522111204. doi:10.1177/10781552211016083

Saleem, R., Cantin, G., Wikström, M., Bolton, G., Kuhns, S., McBride, H. J., et al. (2020). Analytical and Functional Similarity Assessment of ABP 710, a Biosimilar to Infliximab Reference Product. Pharm. Res. 37, 1-23. doi:10. 1007/s11095-020-02816-w

Sankaran, P. K., Kabadi, P. G., Honnappa, C. G., Subbarao, M., Pai, H. V., Adhikary, L., et al. (2018). Identification and Quantification of ProductRelated Quality Attributes in Bio-Therapeutic Monoclonal Antibody via a Simple, and Robust Cation-Exchange HPLC Method Compatible with Direct Online Detection of UV and Native ESI-QTOF-MS Analysis. J. Chromatogr. B 1102-1103, 83-95. doi:10.1016/j.jchromb.2018.10.019

Santos-Neto, J. F., Oliveira, F. O., Hodel, K. V. S., Fonseca, L. M. S., Badaró, R., and MacHado, B. A. S. (2021). Technological Advancements in Monoclonal Antibodies. Scientific World J. 2021, 1-19. doi:10.1155/2021/6663708

Schreiber, S., Yamamoto, K., Muniz, R., and Iwura, T. (2020). Physicochemical Analysis and Biological Characterization of FKB327 as a Biosimilar to Adalimumab. Pharmacol. Res. Perspect. 8. doi:10.1002/prp2.604

Seo, N., Huang, Z., Kuhns, S., Sweet, H., Cao, S., Wikström, M., et al. (2020). Analytical and Functional Similarity of Biosimilar ABP 798 with Rituximab Reference Product. Biologicals 68, 79-91. doi:10.1016/j. biologicals.2020.08.002

Seo, N., Polozova, A., Zhang, M., Yates, Z., Cao, S., Li, H., et al. (2018). Analytical and Functional Similarity of Amgen Biosimilar ABP 215 to Bevacizumab. MAbs 10, 678-691. doi:10.1080/19420862.2018.1452580

Sharma, D. K., King, D., Oma, P., and Merchant, C. (2010). Micro-flow Imaging: Flow Microscopy Applied to Sub-visible Particulate Analysis in Protein Formulations. AAPS J. 12, 455-464. doi:10.1208/s12248-010-9205-1 
Shatat, S. M., Eltanany, B. M., Mohamed, A. A., Al-Ghobashy, M. A., Fathalla, F. A., and Abbas, S. S. (2018). Coupling of On-Column Trypsin DigestionPeptide Mapping and Principal Component Analysis for Stability and Biosimilarity Assessment of Recombinant Human Growth Hormone. J. Chromatogr. B 1072, 105-115. doi:10.1016/j.jchromb.2017. 11.007

Sheen, D. A., Shen, V. K., Brinson, R. G., Arbogast, L. W., Marino, J. P., and Delaglio, F. (2020). Chemometric Outlier Classification of 2D-NMR Spectra to Enable Higher Order Structure Characterization of Protein Therapeutics. Chemometrics Intell. Lab. Syst. 199, 103973. doi:10.1016/j.chemolab.2020. 103973

Shekhawat, R., Shah, C. K., Patel, A., Srinivasan, S., Kapoor, P., Patel, S., et al. (2019). Structural Similarity, Characterization of Poly Ethylene Glycol Linkage and Identification of Product Related Variants in Biosimilar Pegfilgrastim. PLoS ONE 14, e0212622. doi:10.1371/journal.pone.0212622

Shen, Z., Wang, Y., Xu, H., Zhang, Q., Sha, C., Sun, B., et al. (2021). Analytical Comparability Assessment on Glycosylation of Ziv-Aflibercept and the Biosimilar Candidate. Int. J. Biol. Macromolecules 180, 494-509. doi:10. 1016/j.ijbiomac.2021.03.020

Shi, Y., Li, Z., and Lin, J. (2012). Advantages of CE-SDS over SDS-PAGE in mAb Purity Analysis. Anal. Methods 4, 1637-1642. doi:10.1039/ c2ay25208b

Singh, S. K., Narula, G., and Rathore, A. S. (2016). Should Charge Variants of Monoclonal Antibody Therapeutics Be Considered Critical Quality Attributes? Electrophoresis 37, 2338-2346. doi:10.1002/elps.201600078

Singh, S. K., Pokalwar, S., Bose, S., Gupta, S., Almal, S., and Ranbhor, R. S. (2018). Structural and Functional Comparability Study of Anti-CD20 Monoclonal Antibody with Reference Product. Btt 12, 159-170. doi:10.2147/BTT.S187744

Singleton, C. A. (2014). MS in the Analysis of Biosimilars. Bioanalysis 6, 1627-1637. doi:10.4155/bio.14.110

Skala, W., Wohlschlager, T., Senn, S., Huber, G. E., and Huber, C. G. (2018). MoFi: A Software Tool for Annotating Glycoprotein Mass Spectra by Integrating Hybrid Data from the Intact Protein and Glycopeptide Level. Anal. Chem. 90, 5728-5736. doi:10.1021/ACS.ANALCHEM.8B00019

Skrlin, A., Radic, I., Vuletic, M., Schwinke, D., Runac, D., Kusalic, T., et al. (2010). Comparison of the Physicochemical Properties of a Biosimilar Filgrastim with Those of Reference Filgrastim. Biologicals 38, 557-566. doi:10.1016/j. biologicals.2010.05.002

Song, Y. E., Dubois, H., Hoffmann, M., Deri, S., Fromentin, Y., Wiesner, J., et al. (2021). Automated Mass Spectrometry Multi-Attribute Method Analyses for Process Development and Characterization of mAbs. J. Chromatogr. B 1166, 122540. doi:10.1016/j.jchromb.2021.122540

Sorensen, M., Harmes, D. C., Stoll, D. R., Staples, G. O., Fekete, S., Guillarme, D., et al. (2016). Comparison of Originator and Biosimilar Therapeutic Monoclonal Antibodies Using Comprehensive Two-Dimensional Liquid Chromatography Coupled with Time-Of-Flight Mass Spectrometry. MAbs 8, 1224-1234. doi:10.1080/19420862.2016.1203497

Sörgel, F., Lerch, H., and Lauber, T. (2010). Physicochemical and Biologic Comparability of a Biosimilar Granulocyte colony-stimulating Factor with its Reference Product. BioDrugs 24, 347-357. doi:10.2165/11585100000000000-00000

Sörgel, F., Schwebig, A., Holzmann, J., Prasch, S., Singh, P., and Kinzig, M. (2015). Comparability of Biosimilar Filgrastim with Originator Filgrastim: Protein Characterization, Pharmacodynamics, and Pharmacokinetics. BioDrugs 29, 123-131. doi:10.1007/s40259-015-0124-7

Stoll, D. R., Harmes, D. C., Danforth, J., Wagner, E., Guillarme, D., Fekete, S., et al. (2015). Direct Identification of Rituximab Main Isoforms and Subunit Analysis by Online Selective Comprehensive Two-Dimensional Liquid Chromatography-Mass Spectrometry. Anal. Chem. 87, 8307-8315. doi:10. 1021/acs.analchem.5b01578

Suba, D., Urbányi, Z., and Salgó, A. (2015). Capillary Isoelectric Focusing Method Development and Validation for Investigation of Recombinant Therapeutic Monoclonal Antibody. J. Pharm. Biomed. Anal. 114, 53-61. doi:10.1016/j.jpba. 2015.04.037

Szekrenyes, A., Szigeti, M., Dvorakova, V., Jarvas, G., and Guttman, A. (2020). Quantitative Comparison of the N-Glycosylation of Therapeutic Glycoproteins Using the Glycosimilarity Index. A Tutorial. Trac Trends Anal. Chem. 122, 115728. doi:10.1016/j.trac.2019.115728
Tan, Q., Guo, Q., Fang, C., Wang, C., Li, B., Wang, H., et al. (2012). Characterization and Comparison of Commercially Available TNF Receptor 2-Fc Fusion Protein Products. MAbs 4, 761-774. doi:10.4161/ mabs. 22276

TGA (2018). Biosimilar Medicines Regulation: Therapeutic Goods Administration: Version 2.2. Available at: https://www.tga.gov.au/publication/biosimilarmedicines-regulation (Accessed June 9, 2021).

Thennati, R., Singh, S., Nage, N., Patel, Y., Bose, S., Burade, V., et al. (2018). Analytical Characterization of Recombinant hCG and Comparative Studies with Reference Product. Btt 12, 23-35. doi:10.2147/BTT.S141203

USFDA (2018). Biological Product Definitions. Available at: https://www.fda.gov/ files/drugs/published/Biological-Product-Definitions.pdf (Accessed May 3, 2021).

USFDA (2021). Biosimilar Product Information. Available at: https://www.fda. gov/drugs/biosimilars/biosimilar-product-information (Accessed June 9, 2021).

USFDA (2019). Draft Guidance: Development of Therapeutic Protein Biosimilars: Comparative Analytical Assessment and Other Quality-Related Considerations.

USFDA (2015). Guidance for Industry: Quality Considerations in Demonstrating Biosimilarity of a Therapeutic Protein Product to a Reference Product. Available at: http://www.fda.gov/ Drugs/GuidanceComplianceRegulatoryInformation/Guidances/defaulthtmand/orhttp:// www.fda.gov/BiologicsBloodVaccines/GuidanceComplianceRegulatoryInformation/ Guidances/defaulthtm (Accessed June 9, 2021).

USFDA (2016). Regulatory Consideration for the Characterization of HOS in Biotechnology Products.

USFDA (2017). Statistical Approaches to Evaluate Analytical Similarity - Guidance for Industry. Silver Spring, Maryland: FDA Guid. Ind.

Vanhoenacker, G., Vandenheede, I., David, F., Sandra, P., and Sandra, K. (2015). Comprehensive Two-Dimensional Liquid Chromatography of Therapeutic Monoclonal Antibody Digests. Anal. Bioanal. Chem. 407, 355-366. doi:10. 1007/s00216-014-8299-1

Velasco-Velázquez, M., Salinas-Jazmín, N., Hisaki-Itaya, E., Cobos-Puc, L., Xolalpa, W., González, G., et al. (2017). Extensive Preclinical Evaluation of an Infliximab Biosimilar Candidate. Eur. J. Pharm. Sci. 102, 35-45. doi:10.1016/ j.ejps.2017.01.038

Visser, J., Feuerstein, I., Stangler, T., Schmiederer, T., Fritsch, C., and Schiestl, M. (2013). Physicochemical and Functional Comparability between the Proposed Biosimilar Rituximab GP2013 and Originator Rituximab. BioDrugs 27, 495-507. doi:10.1007/s40259-013-0036-3

Wagner, E., Colas, O., Chenu, S., Goyon, A., Murisier, A., Cianferani, S., et al. (2020). Determination of Size Variants by CE-SDS for Approved Therapeutic Antibodies: Key Implications of Subclasses and Light Chain Specificities. J. Pharm. Biomed. Anal. 184, 113166. doi:10.1016/j.jpba.2020.113166

Wang, D., Park, J., Patil, S. M., Smith, C. J., Leazer, J. L., Keire, D. A., et al. (2020). An NMR-Based Similarity Metric for Higher Order Structure Quality Assessment Among U.S. Marketed Insulin Therapeutics. J. Pharm. Sci. 109, 1519-1528. doi:10.1016/j.xphs.2020.01.002

Wang, T., and Chow, S.-C. (2017). On the Establishment of Equivalence Acceptance Criterion in Analytical Similarity Assessment. J. Biopharm. Stat. 27, 206-212. doi:10.1080/10543406.2016.1265539

Wen, J., Lord, H., Knutson, N., and Wikström, M. (2020). Nano Differential Scanning Fluorimetry for Comparability Studies of Therapeutic Proteins. Anal. Biochem. 593, 113581. doi:10.1016/j.ab.2020.113581

WHO (2013). Expert Committee on Biological Standardization: Guidelines on Evaluation of Monoclonal Antibodies as Similar Biotherapeutic Products (SBPs) - Annex 2.

WHO (2009). Final Expert Committee on Biological Standardization: Guidelines on Evaluation of Similar Biotherapeutic Products (SBPs).

Wildner, S., Huber, S., Regl, C., Huber, C. G., Lohrig, U., and Gadermaier, G. (2019). Aptamers as Quality Control Tool for Production, Storage and Biosimilarity of the Anti-CD20 Biopharmaceutical Rituximab. Sci. Rep. 9 (9), 1-14. doi:10.1038/s41598-018-37624-1

Wojtyra, U. (2021). Smart \& Biggar: Update on Biosimilars in Canada - April 2021. Available at: https://www.smartbiggar.ca/insights/publication/update-onbiosimilars-in-canada-april-2021 (Accessed June 9, 2021).

Xie, L., Zhang, E., Xu, Y., Gao, W., Wang, L., Xie, M. H., et al. (2020). Demonstrating Analytical Similarity of Trastuzumab Biosimilar HLX02 to Herceptin with a Panel of Sensitive and Orthogonal Methods Including a 
Novel Fc $\gamma$ RIIIa Affinity Chromatography Technology. BioDrugs 34, 363-379. doi:10.1007/s40259-020-00407-0

Xu, J., Shao, Z., Han, X., Huang, Y., Zou, X., and Shen, Y. (2021). Similarity Assessment by Multivariate Statistics Method Based on the Distance between Biosimilar and Originator. Bioresour. Bioproc. 8, 24. doi:10.1186/s40643-02100378-2

Xu, Y., Xie, L., Zhang, E., Gao, W., Wang, L., Cao, Y., et al. (2019). Physicochemical and Functional Assessments Demonstrating Analytical Similarity between Rituximab Biosimilar HLX01 and the MabThera. MAbs 11, 606-620. doi:10. 1080/19420862.2019.1578147

Yu, C., Zhang, F., Xu, G., Wu, G., Wang, W., Liu, C., et al. (2020). Analytical Similarity of a Proposed Biosimilar BVZ-BC to Bevacizumab. Anal. Chem. 92, 3161-3170. doi:10.1021/acs.analchem.9b04871

Zhang, E., Xie, L., Qin, P., Lu, L., Xu, Y., Gao, W., et al. (2020). Quality by DesignBased Assessment for Analytical Similarity of Adalimumab Biosimilar HLX03 to Humira. AAPS J. 22, 1-14. doi:10.1208/s12248-020-00454-z

Zhao, S. S., and Chen, D. D. Y. (2014). Applications of Capillary Electrophoresis in Characterizing Recombinant Protein Therapeutics. Electrophoresis 35, 96-108. doi:10.1002/elps.201300372

Zheng, J., Yin, D., Yuan, M., and Chow, S.-C. (2019). Simultaneous Confidence Interval Methods for Analytical Similarity Assessment. J. Biopharm. Stat. 29, 920-940. doi:10.1080/10543406.2019.1657142
Zhu, G., Sun, L., Heidbrink-Thompson, J., Kuntumalla, S., Lin, H.-y., Larkin, C. J., et al. (2016). Capillary Zone Electrophoresis Tandem Mass Spectrometry Detects Low Concentration Host Cell Impurities in Monoclonal Antibodies. Electrophoresis 37, 616-622. doi:10.1002/elps.201500301

Conflict of Interest: The authors declare that the research was conducted in the absence of any commercial or financial relationships that could be construed as a potential conflict of interest.

Publisher's Note: All claims expressed in this article are solely those of the authors and do not necessarily represent those of their affiliated organizations, or those of the publisher, the editors and the reviewers. Any product that may be evaluated in this article, or claim that may be made by its manufacturer, is not guaranteed or endorsed by the publisher.

Copyright (c) 2022 Nupur, Joshi, Gulliarme and Rathore. This is an open-access article distributed under the terms of the Creative Commons Attribution License (CC $B Y$ ). The use, distribution or reproduction in other forums is permitted, provided the original author(s) and the copyright owner(s) are credited and that the original publication in this journal is cited, in accordance with accepted academic practice. No use, distribution or reproduction is permitted which does not comply with these terms. 